\title{
Aproveitamento Analítico da Extratibilidade de Sais de Fosfônio na Separação e Determinação de Irídio, Ródio e Ósmio
}

\section{JAIM LICHTIG}

Tese de Doutoramento apresentada ao Departamento de Quimica Fundamental do Instituto de Quimica da Universidade de São Paulo.

Orientador: Prof. Dr. PASCHOAL SENISE

São Paulo

1971 
Ao Professor senise, cuja eficiente e segura orientaçāo cientifica contribuiu diretamente na minha formaçāo, meus sinceros agradecimentos. 
A você, querioA 
Meus agradecimentos ā Fundação de Amparo à Pesquisa do Estado de são Paulo e à Fond Foundation, pe las bôlsas concedidas.

\footnotetext{
Aos colegas e funcionārios do Instituto que, pela cola. boraçāo prestada na elaboração dêste trabalho; meus agradecimentos.
}
A Carminha pelo desvêlo dispensado na datilogra fia dêste trabalho e ao Matsuyoshi Mori pelo cuidado demonstrado na execuçäo dos desentros, agradeço. 
PAG.

I. CONSIDERAÇÕRA GERAIS ..................... 11

Ia. Separaçōes iridio-r6đio: métodos exdg tentes ................................. 11

Ib. Os sais "Ônio" e seus usos ........... 12

Ic. Metil n-propil e metil 1-propil fogfôn:lo ........................... 14

II. SEPARAGÃo IRIDIO-RODIO..................$\left.\right|^{15}$

IIa. Estudo do comportamento dos bromocomplexos de irldio e ródio .......... 15

IIb. Estudo do comportamento dos cloro-com plexos de irldio e r6dio .............. 17

tixI. DETERKLINAÇÃO DE IRIDIO EM PRESENĢA DE RODIO E DE OUTROS IONS ........................... 20

IIIa. Espectro de absorção, lei de Beex e diagrama de Ringbom .................... 20

IIIb. Separações Ir-Rh $\ldots . \ldots \ldots \ldots \ldots \ldots \ldots \ldots$........ 22

IIIC. Estudos de interferentes: $\mathrm{Pd}(I I)$, Pt(IV), os(IV) e outros .............. 25

IIId. Bstudos de interferentes:anions ...... 32

IIIe. Eficiência da extração ............... 33

IIIf. Estudo da precisão do método ......... 35

IIIg. Procedimento .......................... 36 
PAQ.

IV. DETERYINAÇÃO ESPECTROFOTOMB TRICA DE RO-

DIO $\ldots \ldots \ldots \ldots \ldots \ldots \ldots \ldots \ldots \ldots \ldots \ldots \ldots \ldots \ldots$

IVa. Estudos preliminares ................

IVb. Espectro de absorção, le1 de Beer e diagrama de Ringbom ................. 38

IVc. Determinação Ir-Rh ............... 42

IVd. Eficiência da extração ............. 45

IVe. Estudo da precisão do metodo ......... 46

IVf. Procedimento ..................... 48

IVg. Esquema de separação .............. 48

v. MATUREZA dOS COMPOSTOS ................ 50

VI. SEPARAĢ̃O DE OS(IV) DA SOLUGÃO INICIAL ....: 50

vIa. Considerações preliminares ......... 50

VIb. Espectro de absorção, lei de Beer e diagrana de Ringbom ................ 54

VIc. Separações Os(IV)-Pt(IV), Pd(II) ... 58

vId. Estudo da precisão do mátodo ........ 59

vIe. Procedimento ...................... 60

VIf. Esquema de separação ................ 61

VII. CONSIDERAÇŐ́rS FINAIS .................. 63

VIII. DETALHES EXPERIMESTAIS ................ 68

VIIIan Reagentes, soluçōes e aparelhagem ... 68

VIIIb. Eliminação de interferentes ......... 71

VIIIc. Isolamento e anslise dos compostos .. . 72

SUMARIO $\ldots \ldots \ldots \ldots \ldots \ldots \ldots \ldots \ldots \ldots \ldots \ldots \ldots \ldots 75$

BIBLIOGRAPIA $\ldots \ldots \ldots \ldots \ldots \ldots \ldots \ldots \ldots \ldots \ldots \ldots, 77$ 


\section{CONSIDERAÇŌES GERAIS}

Ia. Separações irldio-r6dio: métodos existentes.

"A separação iridio-rbdio apresenta-se como o aspecto de maior dificuldade na análise dos metais do grupo da platina", segundo BEAMISH

(1) Assim, ate re centemente, poucos métodos puderam ser considerados razoáveis sendo a maioria de procedimento moroso e complexo $e$, não raro, limitados a pequenas quantidades dos dois metais em questão. Podemos citar un dos primeiros métodos de separação ródio-iridio pela fusão da mistura dos metais do grupo da platina com hidrogenossulfato de sbdio, apbs o qual o ródio era extraldo em agua: porén, o método apresenta defeitos pois nem sempre se consegue a dissolução seletiva do metal. Tambêm a separação rodio-iridio usando-se sulfeto de sodio, alem de não ser bastante precisa, aplicável apenas a pequenas quantidades de rbdio $(2,3)$. Por outro 1ado, a separação de iridio da mistura dos dois metais como dibxido, obtido pela hidrblise dos lons $\operatorname{Ir}$ (IV) com Ions hidrogenocarbonato, mostrou não ter boa precisão (4) assim como a separação entre ambos pela redução de r6dio com cobre $(5,6)$. Com relação ao uso do cobre na separaç̃o, un metodo de melhor precisão fol elaborado porkm, exaustivo na sua execução (7), assim como quan do se substituiu o cobre por antimônio para reduzir ródio na mistura $(8,9)$; resultados imprecisos obtiveram se quando se substituiu o cobre e 0 antimonio por lons redutores como $\mathrm{TI}$ (III) ${ }^{(10)}, \mathrm{Cr}$ (II) (11). Certas sepa-. 
rações rodio-iridio obtiveran-se en condições especiais através dè resina de troca iônica $(12,13,14,15)$. A busca de uma melhora na precisão da separação levou a aplicação de outros princípios. Assim, metodos baseados na extração en solventes orgânicos foram elaborados com a extração do r6dio, em mistura com iridio, com alcool iso amilico (16), por(km limitados a baipos teores de ambos.

Outras separações por extração dos complexos foram elaborados mediante 0 uso de fosfato de tri n-buti la $(17,18)$, 1gualmente exaustivas. Também morosas mostraram-se as extrações dos metais do grupo da platina com sucessivos retôrnos a fase aquosa utilizando-se $\mathrm{snCl}_{2}, \mathrm{SnBr}_{2}$ e fosfato de tri n-butila $(19,20)$.

Uma série de estudos interessantes de extração de metais do grupo da platina pelo uso de aminas foram publicados, sendo alguns dêles relativos a separação ródio-iridio em especial; com trioctilamina em benzeno (21); com sais de triisobutilamônio (22); com triisoctil amina em metil i-butil cetona (23), com brometo de tetra octilamônio em acido caprilico (24); com aminas primárias e sais de amônio $(25,26,27)$.

Ib. Os sais "ônion e seus usos.

A separação e determinação dos metais do grupo da platina por extração de seus halogeno e pseudo-ha logeno complexos precipitados com lons arsônio e fosfonio, foi objeto de alguns estudos que levaram em certos 
casos a bons resultados. Assim, clöro-complexo de Au(III) precipitado com lons arsônio foi extraldo em cloroformio e determinado espectrofotometricamente ${ }^{(28)}$. NEEB efetuou "spot-tests" baseado na forma microcristalina de precipitados de cloro-complexos de os(IV) con cloreto de tetrafenil,arsônio, cloreto de tetrafenilfosfinio elons de trłfenilmetilarsônio (29); estudos idênticos efetuou para iridio, platina e paládio (30). Cloro-complexo de Os(IV) pre cipitado com lons tetrafenilarsônio extraído com cloroformio e determinado espectrofotometricamente (31). NEEB tamberm efetuou estudos de determinações gravimétricas de Os(IV) e Ir(IV) $(32,33)$ e BODE estudou a determinação gravimétrica de platina, pela precipitação de hexacloroplatinato(IV) de tetrafenilarsônio. (34); paládio foi determina do pela extração de tetratiocianato-paladato(II) de tetra fenilarsônio em cloroformio (35). Por um dos melhores metodos de separação, Ir(IV) foi extraido en clorofbrmio,com - uso de lons tetrafenilfosfônio, encontrando interferências nos outros metais do grupo da platina (36); ainda paIa a extraçĩo do Ir(IV) e Os(IV), ocorre a possibilidadedé utilização de lons 3,4-diclorobenziltrifenilfosfónio (37).

Como se pode notar, são pouquíssimos os metodos altamente eficientes na separação irldio-rbdio e mesmo êsies estão sujeltos a limitações decorrentes das condições ie trabaino.

Tendo em vista amplo estudo realizado e en andafiento em nosso laborat6rio, quanto ao aproveitamento anal1 
tico da diversidade de comportamento de sais de fosfônio, em relação a solventes orgânicos, pensou-se encontrar, dentro dessa linha de investigação, uma solução mais satisfatoria para o problema.

Ic. Metil n-propil e metil 1-propil fosfónio.

Ions trifenil n-propil fosfönio e trifenil 1-propil fosfónio foram usados para amplo estudo sistemático (38) verificando-se apreciáveis diferenças de extratibilidade em solventes orgânicos de sais halogeno e pseudo-halogeno complexos de metais, precipitados com os mesmos. Estudos posteriores resultaram em iden tificacão de $\mathrm{Au}(\mathrm{III})(39,40)$ e separação de $\mathrm{Pt}(\mathrm{IV}) /$ de mistura com Pd(II) (4i).

Esses estudos forneceram indicaçōes de outras possiveis separações de interêsse $e$, consequentemente, deram ensejo a investigações com objetivos especificos, en maior profundidade.

Nêsse sentido, procurou-se dar atenção 20 comportanento dos sais de trifenil n-propil fosfónio e trifenil i-propil fosfónio de halogeno e pseudomaloge no complexos de irldio e rodio, atraves de estudo sistemático. 


\section{SEPARAÇÃO IRIDIO-RODIO}

IIa. Estudo do comportamento dos bromo-complexos de irldio e rodio.

Nosso estudo se dirigiu primeiramente aos bromo-complexos de rodio e iridio pois, en trabalhos anteriores $(38)$, verificou-se haver diferenças de extratibilidade entre saiq de trifenil n-propil fosfônio e trifenil i-propil fosfônio dos bromo-complexos de rb́dio e irldio em alguns solventes. Atraiu-nos tamberm a inten sa côr azul que se obtém em solução aquosa quando se aquece uma solução de Ir(IV) com lons brometo ${ }^{(42)}$ e, Pa ra isso, procurou-se primeiramente estudar essa/reação com finalidades analfticas. Na Tabela I estão reunidos os resultados de ensaios qualitativos efetuados.

Os resultados positivos são, pràticamente insensiveis a variação de $\mathrm{pH}$. Verificou-se, contudo, que inclusive nos casos mais favoráveis ou seja, com ciclohe xanona, 2-metil ciclohexanona e cloroformio, a separação do bromo-complexo de irldio formado com lons trifenil npropil fosfónio não poderia efetuar-se de maneira quanti tativa, mesmo apbs várias extrações. Comprovou-se que êsse fenômeno era devido ao fato de uma parte do iridio (IV) ser reduzida a iridio(III) (43). várias tentativas foram efetuadas a fim de se evitar essa redução, realizando-se a extração em presença de bromo, água oxigenada e en várias concentrações de scido cloridrico (2N,4N, 6N e laN); porem, nenhuma dessas tentativas resultou en sucesso. 
TABELA I

Extração de Sais de Fosfônio de Bromo-Complexos de Iridio(IV)

\begin{tabular}{|c|c|c|}
\hline SOLVENTES & $\begin{array}{l}\text { TRIFENIL } \\
\text { N-PROPJ,L } \\
\text { FOSFOMYO }\end{array}$ & $\begin{array}{l}\text { TRIFENIL } \\
\text { I-PROPI } \\
\text { POSFONIO }\end{array}$ \\
\hline $\begin{array}{l}\text { Alcool n-butilico } \\
\text { Alcool i-butilicip } \\
\text { Alcool n-pentilico } \\
\text { Alcool i-pentilico } \\
\text { Ciclohexanol } \\
\text { 2-metil ciclohexanol } \\
\text { Acetato de etila } \\
\text { Acetato de n-propila } \\
\text { Acetato de n-butila } \\
\text { Acetato de i-butila } \\
\text { Acetato de n-pentila } \\
\text { Acetato de i-pentila } \\
\text { Fosfato de tri n-butila } \\
\text { Metil n-propil cetona } \\
\text { Metil i-propil cetona } \\
\text { Metil i-butil cetona } \\
\text { Metil n-pentil cetona } \\
\text { Metil i-pentil cetona } \\
\text { Metil hexil cetona } \\
\text { Diisobutil cetona } \\
\text { Ciclohexanona } \\
\text { 2-metil ciclohexanona } \\
\text { Anisol } \\
\text { Fenetol } \\
\text { Benzeno } \\
\text { Tolueno } \\
\text { Clorofomio }\end{array}$ & $\begin{array}{r}0 \\
0 \\
0 \\
t \\
+ \\
+ \\
0 \\
0 \\
0 \\
0 \\
0 \\
0 \\
0 \\
t \\
+ \\
t \\
0 \\
0 \\
0 \\
0 \\
++ \\
++ \\
+ \\
0 \\
0 \\
0 \\
++\end{array}$ & $\begin{array}{l}0 \\
0 \\
t \\
t \\
t \\
0 \\
t \\
0 \\
0 \\
0 \\
0 \\
0 \\
0 \\
t \\
t \\
0 \\
0 \\
0 \\
0 \\
0 \\
+ \\
t \\
0 \\
0 \\
0 \\
0 \\
+\end{array}$ \\
\hline
\end{tabular}

Coloração de extrato orgânico: +++ forte; ++ média; + fraca; $t$ (traço) extremamente fraca; 0 incolor. Experimentos efetuados com, aproximadamente, $0,5 \mathrm{ml}$ da fase aquosa ( 5 gotas de solução de bromo-complexo +5 gotas da solução de lons fosfonio a $2 \%$ ) e $0,5 \mathrm{ml}$ do . solvente. 
0 bromo-complexo de Ir.(IV) de trifenil n-propil fosfónio em ciclohexanona apresentou banda caracteristica, com máximo de absorbância en $600 \mathrm{~m}_{\mu}$.

Quanto ao rbdio, verificou-se que, apbs aquecimentto de uma golução de $\mathrm{Rh}$ (III) com lons brometo, seguido de resfriamento e adição de lons fosfônio, havia a formação de um precipitado amarelo enquanto a solução aquosa adquiria coloração violácea $(44,45)$. Apenas - precipitado amarelo era extrafdo parcialmente pelos solventes ja citados.

Devido a esses resultados, passou-se a traba Ihar com os cloro-complexos em lugar dos bromo-complexos.

IIb. Estudo do comportamento dos cloro-complexos de iridio e rodio.

Inicialmente comprovou-se que os cloro-complexos de Ir(III) não precipitam com lons fosfonio, nem são extraldos pelos solventes jh mencionados, enquanto os cloro-complexos de Ir(IV) precipitam com lons fosf $8-$ nio e podem ser extraldos em alguns solventes. Estudou-se o efeito da concentração de ácido cloridrico na solução en várias normalidades ( $2 N, 4 N$ e 6N), não se observando influência na extração, verificando-se apenas que, a medida em que a concentração do ácido aumentava, tornava-se necessario 0 aumento da concentra¿̇ão de lons fosfônio; o efeito persistiu,porém em menor 
intensidade, quando se substituiu $\mathrm{HCl}$ por $\mathrm{H}_{2} \mathrm{SO}_{4}{ }^{\circ}$ Obser vações idênticas foram feitas quảndo se substituíu HCl por $\mathrm{NaCl}$.

Observou-se que, para alguns solventes empregados, a extração dependia diretamente da ordem de adição dcıs reagentes. Assim, em alguıs casos, bons rendimentos foram obtidos quando se adicionou o solvente antes de se adictonar lons fosfônio, ao contrário do que se obtinha quando se invertia a ordem. Isto se pode no tar na Tabela II que rekne dados avaliados com 0 mesmo critério visto anteriormente. Esse fato leva a supor que o solvente tenha participação direta na formação da especie extraível.

Com relação ao $\mathrm{Rh}$ (III), verificou-se que os cloro-complexos não são precipitados pelos sais de fosfônio empregados, nem são extrádos. Observando-se a Tabela II, nota-se que os melhores rendimentos na extra ção foram obtidos com metil n-propil cetona, metil ipropil cetona e 2-metil ciclohexanona, quando adicionados antes doslons trifenil n-propil fosfônio. Con relação aos lons trifenil 1-propil fosfonio, a adição dos mesmos (ou do solvente) pouco afetou o resultado da ex tração. :

Nosso estudo visou inicialmente a separação iridio-rbdio pela extração de Ir(IV) através de solventes menos densos que a agua, o que facilitaria a operação. Porém, verificou-se que a permanência dos cloro- 
TABELA II

Extração de sais de Fosfônto de Cloro-Complexos

de IrIdio(IV)

\begin{tabular}{|c|c|c|c|c|}
\hline SOLVENTE & $\begin{array}{l}\text { 12) TWPF } \\
0_{22} \text { ) SOLV }\end{array}$ & $\begin{array}{l}\text { 29) SOLV } \\
\text { 22) TMPP }\end{array}$ & $\begin{array}{l}\text { \#* 19) TIPF } \\
\text { 22) SOLV }\end{array}$ & $\begin{array}{l}\text { 12) SOLV } \\
22) \mathrm{TIPP}\end{array}$ \\
\hline Alcool n-butilico & + & $t$ & + & + \\
\hline Alcool i-butllico & + & $t$ & + & $t$ \\
\hline Alcool n-pentilico & + & $\mathbf{t}$ & $\mathbf{0}$ & 0 \\
\hline Alcool i-pentilico & + & $t$ & $\mathbf{0}$ & 0 \\
\hline Ciclohexanol & + & $t$ & + & $t$ \\
\hline 2-metil ciclohexanol & + & $\mathbf{t}$ & + & $\mathbf{t}$ \\
\hline Acetato de etila & + & $t$ & $\mathbf{0}$ & 0 \\
\hline Acetato de n-propila & + & $t$ & $\mathbf{0}$ & 0 \\
\hline Acetato de n-butila & $\mathbf{t}$ & $\mathbf{0}$ & $\mathbf{0}$ & 0 \\
\hline Acetato de i-butila & 0 & 0 & 0 & 0 \\
\hline Acetato de n-pentila & + & + & 0 & + \\
\hline Acetato de i-pentila & + & 0 & 0 & 0 \\
\hline Fosfato de tri n-butila & $t$ & $t$ & $\mathbf{t}$ & $\mathbf{t}$ \\
\hline Metil n-propil cetona & + & +++ & ++ & + \\
\hline Metil i-propil cetona & + & +++ & t+ & + \\
\hline Metil 1-butil cetona & ++ & t & ++ & $\mathbf{t}$ \\
\hline Metil n-pentil cetona & + & ++ & + & + \\
\hline Metil i-pentil cetona & + & $+t$ & + & + \\
\hline Metil hexil cetona & + & + & + & $t$ \\
\hline Diisobutil cetona & + & $t$ & 0 & 0 \\
\hline Ciclohexanona & t+ & ++ & + & + \\
\hline 2-metil ciclohexanona & + & $t+t$ & 0 & + \\
\hline Anisol & ++ & + & $t$ & 2 \\
\hline Pẹetol & ++ & $t$ & $t$ & $t$ \\
\hline Benzeno & 0 & 0 & 0 & 0 \\
\hline Tolueno & 0 & 0 & 0 & 0 \\
\hline Cloroformio & +++ & $+t+$ & $+t$ & + \\
\hline
\end{tabular}

TRIFENIL N-PROPIl POSFONIO; * TRIFEMIL I-PROPIl FOSPONIO:

- Solvente. 
complexos de Ir(IV) por certo tempo, em contato com qual quer dos três solventes, a saber: metil n-propil cetona, metil i-propil cetona e 2-metil ciclohexanona, ocasionava descoramento da solução de Ir(IV). 0 descoramento era mais rápido para metil 1-propil cetona, menos para metil n-propil cetona e bastante lento para 2-metil ciclohexanona. Constatou-se que nêsses casos: ocorre redú cão de Ir(IV) conforme e comentado mais adiante (pág.63). Reducões de soluçōes de Ir(IV) a Ir(III) também foran ob servadas por FEDORENKO e IVANOVA nas extraç̄es de clorocomplexos de Ir(IV) com trioctilamina em benzeno (21).

Devido a isso, passou-se a usar cloroformio co mo solvente. Verificou-se que clorofbrmio extrai, quanti tativamente o closomcomplexo de Ir(IV) precipitado com solucões de cloreto de trifenil n-propil fosfonio.

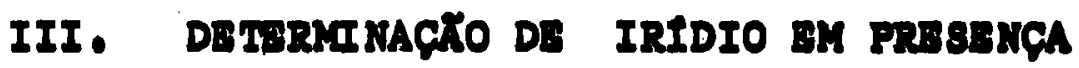
DB RODIO DE OUTROS IONS

IIIa. Espectro de absorção, lei de Beer e aiagrama de Ringbon.

- espectro de absorção de cloró́complexo de Ir(IV) precipitado con lons trifenil n-propil fosfonio e extraido en cloroformio apresenta duas bandas, com mbximos em $494 \mathrm{m \mu}$ e $448 \mathrm{m \mu}$. como se pode ver na Figura 1. A coloraç̃o do extrato mostrou ser estavel. 


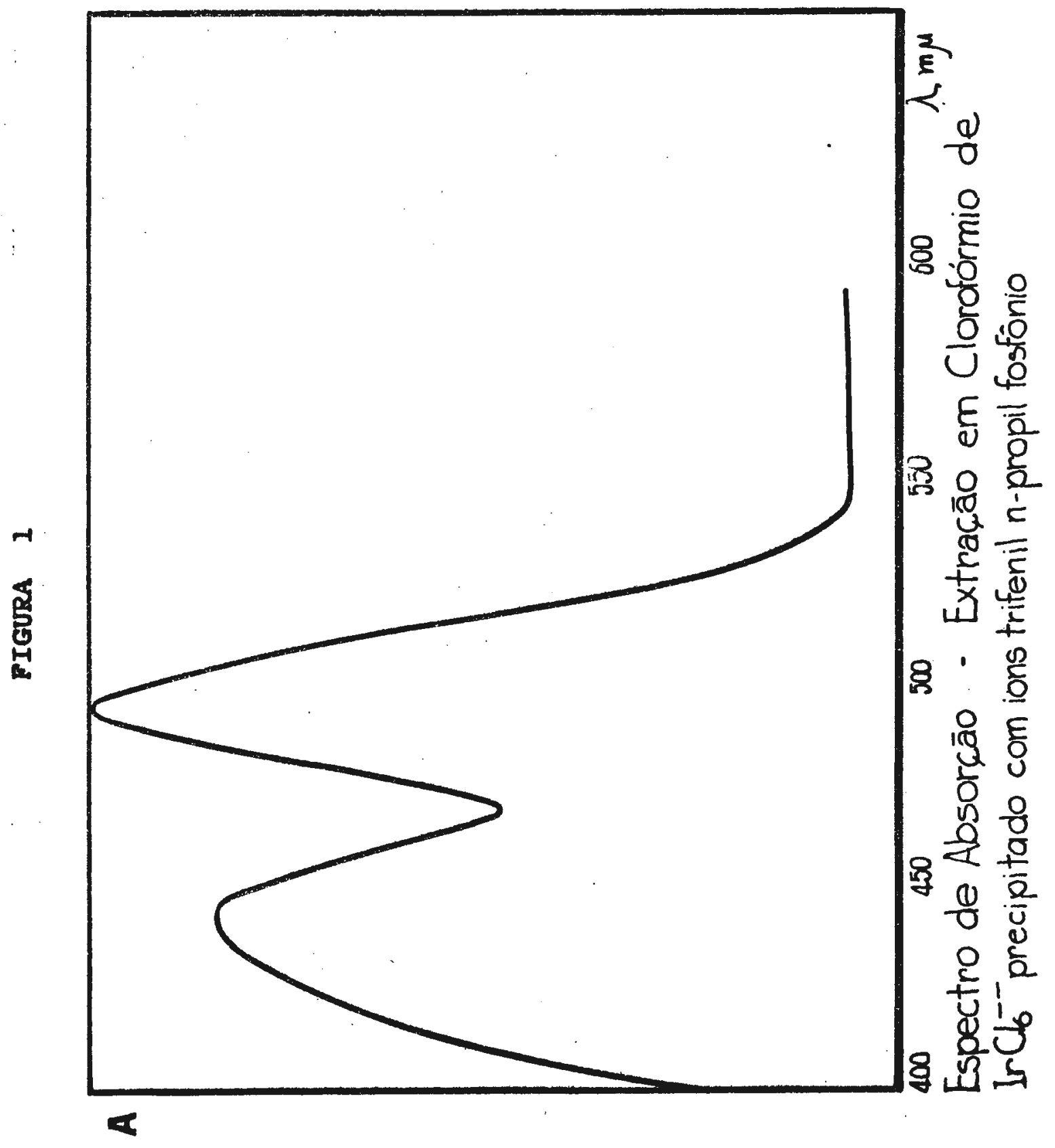


Trabalhando de acôrdo com o procedimento descrito mais adiante ( $p \mathfrak{g}$. 70), verificou-se que a lei de Beer 6 obe decida na faixa de 5,0 a $50,0 \mu \mathrm{g} / \mathrm{ml}$ de $\mathrm{Ir}$ (IV) no extrato or gânico final, em 494 e 448 mu (Figura 2).

o diagrama de Ringbom (46) nos indicou que a meIhor reglão de trabalho corresponde a faixa de $15.0 \mu \mathrm{g} / \mathrm{ml}$ a $35,0 \mu \mathrm{g} / \mathrm{ml}$ na diluiç̃o final $494 \mathrm{~m}_{\mu}$ e $15,0 \mu \mathrm{g} / \mathrm{ml}$ a 30,0 $\mu \mathrm{g} / \mathrm{ml}$ na diluição final $448 \mathrm{m \mu}$ (Figura 3 ).

IIIb. Separação Ir-Rh.

Como os cloro-complexos de $\mathrm{Rh}$ (III) não precipitan com lons fosfônio, nem são extraldos em clorofómio, efetua ram-se algumas determinações de Ir(IV), apos sua separação de $R h(I I I)$. Escolheu-se comprimento de onda èm $494 \mathrm{m \mu}$ para as medidas espectrofotométricas devido a maior absortivi dade. Na Tabela III encontram-se alguns valores.

TABELA III

Separaç̃̃o e Determinacão de Ir(IV) en Mistura com $\mathrm{Rh}$ (III)

\begin{tabular}{|c|c|}
\hline QUANTIDADES PRESENTES $(\mu g)$ & $\begin{array}{c}\text { QUANTIDADES ENCONTRADAS }(\mu \mathrm{g}) \\
\operatorname{Ir}(\mathrm{IV})\end{array}$ \\
\hline $15,0 \mathrm{Ir}(\mathrm{IV}) ; 1500 \mathrm{Rh}(\mathrm{III})$ & 15,$0 ; 14,9 ; 14,9 ; 15,0 ; 14,9$ \\
\hline $35,0 \mathrm{Ir}(\mathrm{IV}) ; 3500 \mathrm{Rh}(\mathrm{III})$ & 35,$0 ; 34,9 ; 34,7 ; 35,0 ; 35,0$ \\
\hline $15,0 \mathrm{Ir}(\mathrm{IV}) ; 3000 \mathrm{Rh}(\mathrm{III})$ & 14,$8 ; 14,9 ; 15,0 ; 15,0 ; 15,0$ \\
\hline $35,0 \operatorname{sp}(\mathrm{IV}), 7000 \mathrm{Bn}(\mathrm{III})$ & $85,0,35,0,34,9135,0135,0$ \\
\hline
\end{tabular}




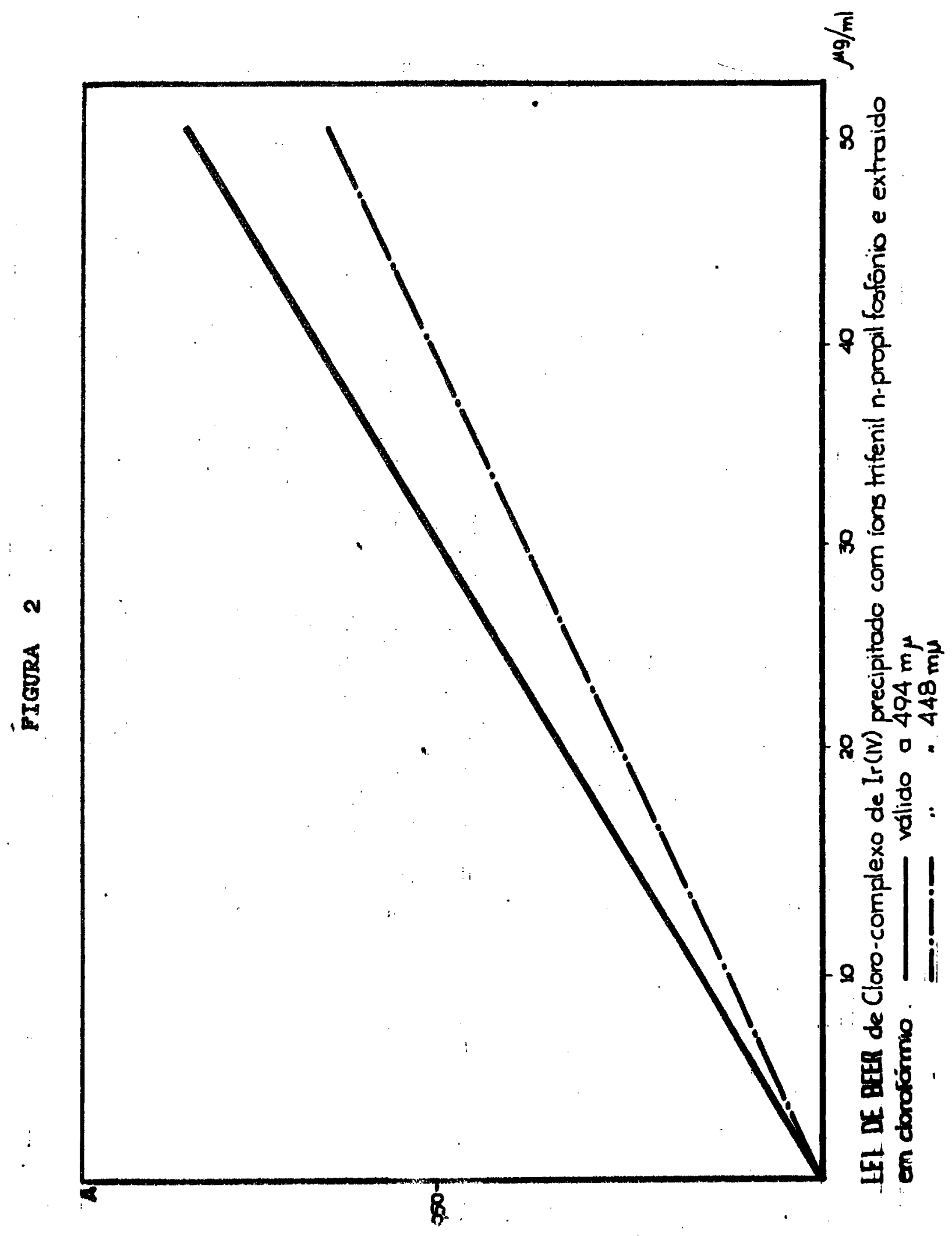




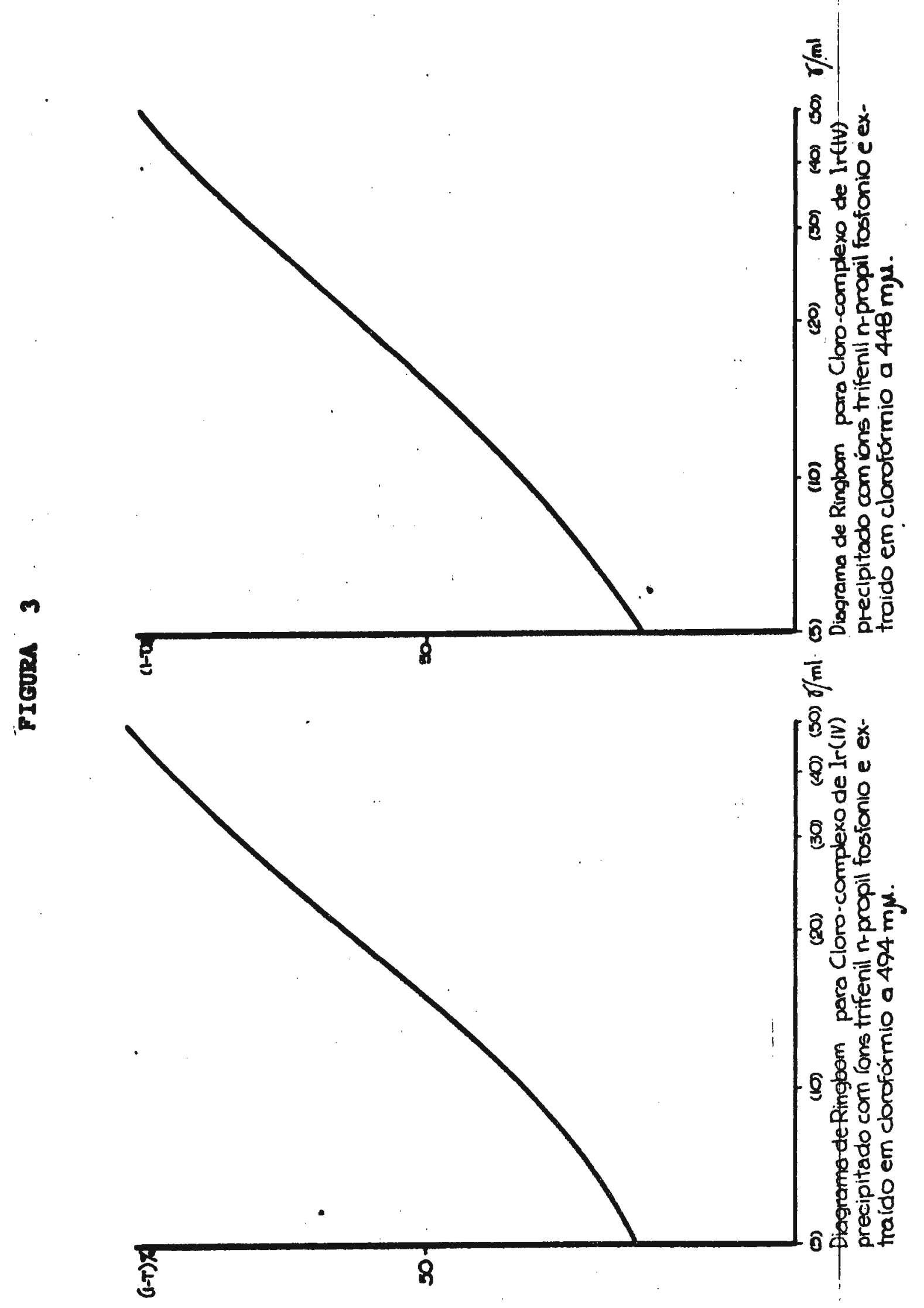


IIIC. Estudos de interferentes; Pd(II), Pt(IV), Os(IV) e outros.

Verificou-se que 0s(III), Ru(III) e Fe(III)nessas conđiç̧̃es, não interferem. Determinações de Ir(IV) em presença de grandes quantidades de Os(III). Ru(III) e Fe(III) efetuaram-se com bons resultados, como se pode ver na Tabe la IV.

TABELA IV

Separação de Irldio de Soluções Contendo Diversos Ions Metalicos

IONS INTERPERENTES $(\mu \mathrm{g})$

$\operatorname{Ir}(I V)(\mu g)$

PRESBNTB

ENCONTRADO

\begin{tabular}{|c|c|c|}
\hline $7000 \mathrm{Rh}($ III $): 7000 \mathrm{Fe}($ III ) & 35,0 & 34,$9 ; 35,0 ; 35,0$ \\
\hline $\begin{array}{l}7000 \mathrm{Rh}(\text { III }): 7000 \mathrm{Fe}(\mathrm{III}): \\
7000 \mathrm{Ru}(\mathrm{III})\end{array}$ & 35,0 & 35,$0 ; 35,0 ; 34,8$ \\
\hline $\begin{array}{l}7000 \mathrm{Rh}(\text { III }): 7000 \mathrm{Fe}(\mathrm{III}) ; \\
3000 \mathrm{Os}(\mathrm{III})\end{array}$ & 35,0 & 34,$9 ; 35,0 ; 34,8$ \\
\hline
\end{tabular}

Em seguida, estudou-se a possibilidade de se elimi nax Pd(II), Pt(IV) e Os(IV) pois os cloro-complexos dos mes mos precipitam com lons trifenil n-propll fosfonio e os reg pectivos precipitados são extraldos em clorofbrmio. A extração dêsses precipitados com outro solvente, anteriormente a adição de clorof6rmio, não forneceu resultados satisfa tórios pois o cloro-complexo de $\operatorname{Ir}(I V)$ tambem era extraldo 
nos solventes empregados.

Então, aproveitou-se o fato de cloro-complexo de Ir(III) não precipitar con lons fosfônio, nem ser extraldo. Assim, Ir(IV) foi reduzido a Ir(III) en solução aquosa $e$, nessas condições, os metais acima re feridos foran precipitados com lons fosfónio e extraldos. Ap6s a eliminação dêsises interferentes, oxidouse novamente o iridio e o procedimento teve sequencia (ver pá.36). Tentou-se vários redutores: hidrazina, hidroxilamina, Ions sulfito e acido ascórbico. Bste hl timo fol o que proporcionou melhores resultados.Então, a solução original contendo Ir(IV) e os lons em estudo, adicionou-se acido ascópbico para reduzir Ir(IV) a Ir(III): a seguir, a adiç̃o de lons fosfonio e clorof6rmio, possibilitou a extração dos interferentes cita dos há pouco: a solução aquosa resultante, adicionouse un oxidante para reoxidar. Ir(III) a Ir(IV) e,com is so, retornar na separação iridionbdio.

Com relação aos oxidantes, muitos foran expe rimentados: $\mathrm{MnO}_{4}{ }^{-} \cdot \mathrm{S}_{2} \mathrm{O}_{8}-\mathrm{H}_{2} \mathrm{O}_{2}$ e Sgra de cloro, sendo que este altimo apresentou melkores resultados. Assti. apbs eliminacão dos interferentes, adicionoumge sou de cloro a solucăo, segulda de lons fosfonio e cloroSormio, a edin de obter a separagio de Ir(IV). Para isso, adotou-se um procedimento que se tornou definitivo - que se acha a plg. 36.

A separação de irldio pela extraç̃o en cloro formio de cloro-complexo de Ir(IV) precipitado con long. 
fosfônio efetua-se muito bem em meio fortemente acido, a partif de $\mathrm{pH}=2,0 \mathrm{com}$ acidez crescente. O melhor intervalo para a extração entre $\mathrm{pH}=1,5$ e $\left[\mathrm{H}^{+}\right]=2,0$. Alguns dados obtidos peła aplicação do procedimento estabelecido estão reunidos na Tabela V.

\section{TABELA V}

Separação de $\operatorname{Ir}(I V)$ de Soluções Contendo Diversos Ions Metálicos

IONS INTERFERENTES $(\mu \mathrm{g})$

PRESENTB
$\operatorname{Ir}($ IV) $(\mu \mathrm{g})$

ENCONTRADO

\begin{tabular}{|c|c|c|}
\hline $1500 \mathrm{Pt}(\mathrm{I} \hat{\mathrm{V}})$ & 15,0 & 14,$9 ; 14,9 ; 15,0$ \\
\hline $3000^{?}$ Pt (IV) & 15,0 & 14,$9 ; 14,8 ; 14,9$ \\
\hline $3000 \mathrm{Rh}(\mathrm{III}) ; 3000 \mathrm{Pt}(\mathrm{IV})$ & 15,0 & 14,$9 ; 14,9 ; 14,8$ \\
\hline $\begin{array}{l}3000 \mathrm{Rh}(\mathrm{III}) ; 3000 \mathrm{Pd}(\mathrm{II}) ; \\
3000 \mathrm{Pt}(\mathrm{IV})\end{array}$ & 15,0 & 14,$9 ; 14,8 ; 14,9$ \\
\hline $3500 \mathrm{Pt}(\mathrm{IV})$ & 35,0 & 34,$8 ; 34,9 ; 34,9$ \\
\hline $7000 \mathrm{Pt}(\mathrm{IV})$ & 35,0 & 34,$9 ; 34,9 ; 34,9$ \\
\hline $7000 \mathrm{Rh}(\mathrm{III}) ; 3500 \mathrm{Pt}$ (IV) & 35.0 & 34,$9 ; 34,8$ \\
\hline $7000 \mathrm{Rh}($ III ):7000 Pt(IV) & 35,0 & 34,$9 ; 34,9 ; 35,0$ \\
\hline $\begin{array}{l}\text { 7000 } \mathrm{Rh}(\mathrm{III}): 7000 \mathrm{Pt}(\mathrm{IV}) ; \\
7000^{\mathrm{Ru}(\mathrm{III})}\end{array}$ & 35,0 & 34,$9 ; 34,8 ; 34,9$ \\
\hline $\begin{array}{l}7000 \mathrm{Rh}(\mathrm{III}) ; 7000 \mathrm{Pt}(\mathrm{IV}): \\
3500 \mathrm{Pd}(\mathrm{II})\end{array}$ & 35,0 & 34,$8 ; 34,9 ; 34,9$ \\
\hline $\begin{array}{l}7000 \mathrm{Rh}(\mathrm{III}): 7000 \mathrm{Pt}(\mathrm{IV}) ; \\
70 \text { o } \mathrm{Pd}(\mathrm{II})\end{array}$ & 35,0 & 34,$8 ; 34,9 ; 35,0$ \\
\hline $\begin{array}{l}\text { 70po } \mathrm{Rh}(\mathrm{III}) ; 7000 \mathrm{Pt}(\mathrm{IV}) ; \\
70 \text { Os(IV) }\end{array}$ & 35,0 & 35,$0 ; 35,0 ; 34,9$ \\
\hline $\begin{array}{l}7000 \mathrm{Rh}(\mathrm{III}) ; 7000 \mathrm{Cu}(\mathrm{II}) ; \\
7000 \mathrm{Pt}(\mathrm{IV})\end{array}$ & 35,0 & 34,$9 ; 35,0 ; 35,0$ \\
\hline
\end{tabular}


Comprovou-se que Co(II), Ni(II), Cr(III), Al(III), Ti(III) e Th(IV) não interferem e podem estar presentes. Por outro lado, Hg(II), Cd(II), $\mathrm{Zn}$ (II), Bi(III) e Sn(IV) precipitam com lons fosfônio e os precipitados são extraidos em clorofórmio; como êsses extratos em cloroformio são incolores, não interferem na determinação de $\operatorname{Ir}(I V)$. Alguns valores encontram-se re unidos na rabela vI. se houver $\operatorname{sn}($ II), $s$ evidente que se formara $\operatorname{Ir}($ III). Nessas condições, basta adicio nar agua de cloro e o procedimento pode ter sequencia.

$\mathrm{Au}$ (III) interfere, pois seus cloro-complexos precipitam com lons fosfônio e o precipitado $\&$ extraldo em cloroformio. Como $\mathrm{Au}(\mathrm{III})$ é reduzido a Au pelo acido ascórbico, o mesmo não pode ser eliminado conjunta mente com Os(IV), Pt(IV) e Pd(II). Para isso, na solução inicial contida no funil, efetua-se a extração de Au(III) com eter (47), sendo a parte etérica: separada por meio de uma pipeta de extração (48).

$v(v)$ também interferente. obtém-se ums: extrato amarelo de seu sal de fosfónio nas condições de trabalbo. Sua interferência é contornada pela adição preliminar de cêrca de $0,3 \mathrm{ml}$ de śgua oxigenada a $10 \%$ a solução de partida, obtendo-se uma forma de vanddio que não precipita com lons fosfonto e nem extralda em clorof6rmio; em seguida, aplica-se o procedimento usual. 
TABELA VI

Separação de Iridio de Soluções Contendo Diversos

Ions Metálicos

\begin{tabular}{|c|c|c|}
\hline \multirow[b]{2}{*}{ IONS INTERFERENTES $(\mu \mathrm{g})$} & \multicolumn{2}{|c|}{$\operatorname{Ir}(I V) \cdot(\mu g)$} \\
\hline & PRESENTE & ENCONTRADO \\
\hline $\begin{array}{l}3000 \mathrm{Co}(\mathrm{II}) ; 3000 \mathrm{NI} \text { (II): } \\
13000 \mathrm{Al} \text { (III) }\end{array}$ & 15,0 & 15,$0 ; 15,0 ; 14,9$ \\
\hline $3000 \mathrm{Cr}$ (III):3000 Ti(III) & 15,0 . & 15,$0 ; 14,9815,0$ \\
\hline $\begin{array}{l}3000 \mathrm{Cr} \text { (III); } 3000 \mathrm{NI} \text { (II): } \\
3000 \mathrm{Al} \text { (III) }\end{array}$ & 15,0 & 15,$0 ; 15,0,15,0$ \\
\hline $13000 \mathrm{TH}$ (III):3000 $\mathrm{Th}(\mathrm{IV})$ & 25,0 & $15,0: 15,0: 25,0$ \\
\hline $\begin{array}{l}3000 \mathrm{Ti}(\mathrm{III}) ; 3000 \mathrm{Th} \text { (IV): } \\
3000 \mathrm{AI}(\mathrm{III})\end{array}$ & 15,0 & 15,$0 ; 14,9 ; 14,9$ \\
\hline $\begin{array}{l}7000 \mathrm{Co}(\mathrm{II}) ; 7000 \mathrm{Ni}(\mathrm{II}) ; \\
\text { 7000: AI(III) }\end{array}$ & 35,0 & 35,$0 ; 35,0 ; 35,0$ \\
\hline $\begin{array}{l}7000 \mathrm{Cr}(\mathrm{III}): 7000 \mathrm{Ti}(\mathrm{III}): \\
7000 \mathrm{Cu}(\mathrm{IV})\end{array}$ & 35.0 & 35,$0 ; 34,9 ; 34,9$ \\
\hline $\begin{array}{l}7000 \mathrm{Cr} \text { (III);7000 Ni(II); } \\
7000 \mathrm{Al} \text { (III) }\end{array}$ & 35,0 & 35,$0 ; 35,0 ; 34,9$ \\
\hline $\begin{array}{l}7000 \mathrm{Ti}(\mathrm{III}) ; 7000 \mathrm{Th}(\mathrm{IV}) ; \\
7000 \mathrm{Cu}(\mathrm{II})\end{array}$ & 35,0 & 35,$0 ; 34,9 ; 35,0$ \\
\hline $\begin{array}{l}7000 \mathrm{Ti}(\mathrm{III}) ; 7000 \mathrm{Th}(\mathrm{IV}) ; \\
7000 \mathrm{Al}(\mathrm{III})\end{array}$ & 35,0 & 35,$0 ; 35,0 ; 35,0$ \\
\hline $3000 \mathrm{Hg}(\mathrm{II}) ; 3000 \mathrm{Cd}(\mathrm{II})$ & 15,0 & 15,$0 ; 15,0 ; 14,8$ \\
\hline $3000 \mathrm{Hg}(\mathrm{II}) ; 3000 \mathrm{zn}(\mathrm{II})$ & 15,0 & 15,$0 ; 15,0 ; 15,0$ \\
\hline $3000 \mathrm{Cd}(\mathrm{II}) ; 3000 \mathrm{zn}$ (II) & 15,0 & 15,$0 ; 14,9 ; 14,9$ \\
\hline $7000 \mathrm{Hg}(\mathrm{II}) ; 7000 \mathrm{Cd}(\mathrm{II})$ & 35,0 & 35,$0 ; 35,0 ; 35,0$ \\
\hline $7000 \mathrm{Hg}(\mathrm{II}): 7000 \mathrm{zn}$ (II) & 35,0 & 35,$0 ; 35,0 ; 35,0$ \\
\hline $7000 \mathrm{Cd}(\mathrm{II}): 7000 \mathrm{Zn}$ (II) & 35,0 & 34,$9 ; 35,0 ; 35,0$ \\
\hline $7000 \mathrm{BI}(\mathrm{III}): 7000 \mathrm{sn}$ (IV) & 35.0 & 35,$0 ; 35,0 ; 35,0$ \\
\hline
\end{tabular}


$A s(v)$ e $S b(v)$ não interferem na extração de $\operatorname{Ir}(I V)$, No caso de se ter As(III) e Sb(III), inicialmente adicionase água de cloro e o procedimento aplicado. A Tabela vII ilustra alguns resultados obtidos.

TABELA VII

Separação de Iridio de Soluções Contendo Diversos IONS METALICOS

IONS INTERFERENTES $(\mu \mathrm{g})$

$$
\operatorname{Ir}(\text { IV) }(\mu g)
$$

PRESENTE

ENCONTRADO

\begin{tabular}{lll}
\hline $3000 \mathrm{Au}(\mathrm{III})$ & 15,0 & 15,$0 ; 15,0 ; 15,0$ \\
$3000 \mathrm{~V}(\mathrm{~V})$ & 15,0 & 15,$0 ; 14,9 ; 14,9$ \\
$3000 \mathrm{Au}(\mathrm{III}): 3000 \mathrm{Rh}(\mathrm{III})$ & 15,0 & 15,$0 ; 15,0 ; 15,0$ \\
$7000 \mathrm{Au}(\mathrm{III})$ & 35,0 & 35,$0 ; 35,0 ; 34,9$ \\
$7000 \mathrm{v}(\mathrm{V})$ & 35,0 & 35,$0 ; 35,0 ; 35,0$ \\
$7000 \mathrm{Au}(\mathrm{III}) ; 7000 \mathrm{Rh}(\mathrm{III})$ & 35,0 & 35,$0 ; 34,9 ; 35,0$ \\
\hline $\mathbf{i}$ & 15,0 & 15,$0 ; 15,0 ; 15,0$ \\
$3000 \mathrm{As}(\mathrm{V})$ & 15,0 & 14,$9 ; 15,0 ; 15,0$ \\
$3000 \mathrm{sb}(\mathrm{V})$ & 35,0 & 35,$0 ; 34,9 ; 35,0$ \\
$7000 \mathrm{As}(\mathrm{V})$ & 35,0 & 35,$0 ; 35,0 ; 35,0$ \\
$7000 \mathrm{sb}(\mathrm{V})$ & & \\
\hline
\end{tabular}

Com relação a $\mathrm{Ag}(\mathrm{I}), \mathrm{Pb}(\mathrm{II})$, e $\mathrm{TI}(\mathrm{I})$, os mesmos pre cisam estar ausentes e, para 1sso, devem ser eliminados prèviamente. 
Havendo Os(III) na solução inicial, o mesmo permane cerá em mistura com $\operatorname{Ir}$ (III) e $\operatorname{Rh}$ (III), após eliminação de Pd(II) e Pt(IV). Ao se adicionar agua de cloro, Os(III) será oxidado a Os(IV) e êste será precipitado com lons fosfônio e extraido juntamente com Ir(IV). Verificou-ge que no extrato orgânico, a concentração final de os(IV) permissivel para não interferir na medida de $\operatorname{Ir}(\mathrm{IV})$, de $150 \mu \mathrm{g} / \mathrm{ml}$.

Com relação a $\mathrm{Fe}($ III), poderá ser extraido juntamen te com Ir(IV), nas mesmas condịções que o Os(IV)acima $\left(\mathrm{FeCl}_{4}{ }^{-}\right.$ e lon de fosfônio) porém, pelo fato do espectro de absorção do extrato contendo $\mathrm{Fe}$ (III) não interferir na região de medida de $\operatorname{Ir}$ (IV), o mesmo poderá estar presente en várias concentrações. A Tabela vIII ilustra os casos (se as medidas forem realizadas em $448 \mathrm{~m}_{\mu}$. Fe(III) extraido interfere sendo neces sária a adição de lons fluoreto antes de lons fosfónio).

TABELA VIII

Determinação de Ir(IV) na Presença de Vários Ions Metálicos

$$
\begin{aligned}
& 100 \text { Os(IV):35,0 Ir(IV); } \\
& 500 \mathrm{Rh} \text { (III) } \\
& 150 \mathrm{Os} \text { (IV) }: 15.0 \mathrm{Ir} \text { (IV) } \\
& 200 \mathrm{Os}(\mathrm{IV}) ; 15,0 \mathrm{Ir} \text { (IV) } \\
& 7000 \mathrm{Pe}(\mathrm{III}) ; 15,0 \mathrm{Ir}(\mathrm{IV}) \\
& 200 \text { Os(IV):35,0 Ir(IV) } \\
& 1250 \text { Os(IV):35,0 Ir(IV); } \\
& 7000 \mathrm{Pe} \text { (III) }
\end{aligned}
$$$$
34,9 ; 34,9
$$$$
14,9: 15,0
$$$$
15,3: 15,4
$$$$
15,0 ; 15,0
$$$$
35,2 ; 35,2
$$$$
35,0 ; 34,9
$$ 
IIId. Estudos de interferentes: ânions.

Alguns ânions interferem na separação de irldio e devem estar ausentes tais como iodeto, brometo e tiocianato pois suas presencas indicam encontrar-se o iridio na forma de Ir(III).

A eliminação de iodeto $E$ feita pela adiçäo, a solução inicial, no funil, de cêrca de $0,1 \mathrm{ml}$ de sgua oxigenada, seguido da extração do iôdo com benzeno. Os Ions brometo são eliminados nessa fase inicial pela adi ção de cêrca de $0,5 \mathrm{ml}$ de água de cloro, seguido de extração de bromo en cloroformio. Havendo iodeto e brometo presentes, prefere-se usar cloroformio, como solvente, na eliminação do iôdo.

Quanto a tiocianato, sua eliminação e efetua da por meio de lons permanganato adicionados a solução inicial; em seguida, adicionamse algumas gôtas de solu ção de pácido ascorbico e o procedimento e aplicado. os Ions de $\mathrm{Mn}$ (II) e seus cloro-complexos não Interferem.Na Tabela IX encontramos alguns dados referentes a essas eliminaçōes.

Alguns Inions não interferom e podem estar.: presentes na determinação de Ir(IV), como: fluoreto, fog fato, bromato, iodato, sulfato e clorato.

Quanto a lons nitrato e perclorato, os mes:mos precipitan con lons fosfônio e são extraldos 
TABELA Ix

Separação de Iridio de Soluções Contendo

Diversos Anions Interferentes

\begin{tabular}{lll}
\hline $\begin{array}{c}\text { ANIONS } \\
\text { INTERFERENTHS }\end{array}$ & \multicolumn{2}{c}{$\operatorname{Ir(IV)}(\mu \mathrm{g})$} \\
\hline $7000 \mathrm{I}^{-}$ & 35,0 & \multicolumn{1}{c}{ ENCONTRADO } \\
$7000 \mathrm{sCM}^{-}$ & 35,0 & 35,$0 ; 34,9 ; 34,8$ \\
$7000 \mathrm{Br}^{-}$ & 35,0 & 34,$9 ; 35,0 ; 35,0$ \\
$7000 \mathrm{I}^{-} ; 7000 \mathrm{Br}^{-}$ & 35,0 & 35,$0 ; 35,0 ; 35,0$ \\
$3000 \mathrm{sCH}^{-}$ & 15,0 & 34,$8 ; 35,0 ; 35,0$ \\
$3000 \mathrm{I}^{-}$ & 15,0 & 15,$0 ; 15,0$ \\
$3000 \mathrm{Br}^{-}$ & 15,0 & 14,$9 ; 14,9$ \\
\hline
\end{tabular}

clorof6rmio mas não interferem porque os extratos são incolores. Podemos observar alguns dados na rabela $x$.

IIIe. Eficiência da extração.

o coeficiente de extracia foi avaliado numa laixa de concentração compreendendo de $5,0 \mu \mathrm{g} / \mathrm{ml}$ a 50,0 $\mu \mathrm{g} / \mathrm{ml}$ de Ir(IV) na diluição final. Para 1sso, a $1,0 \mathrm{ml}$ da fase aquosa inicial contida no funil de separaçao, adicionaram-se $0,15 \mathrm{ml}$ de $\operatorname{BCl} 12 \%, 1,0 \mathrm{ml}$ de solução de 1 ons fosfonio a $5 \%$ e $2,0 \mathrm{ml}$ de cloropormio.Após agltação, a 
TABELA $x$

Separação de Irldio(IV) de soluções Contendo

Diversos Anions

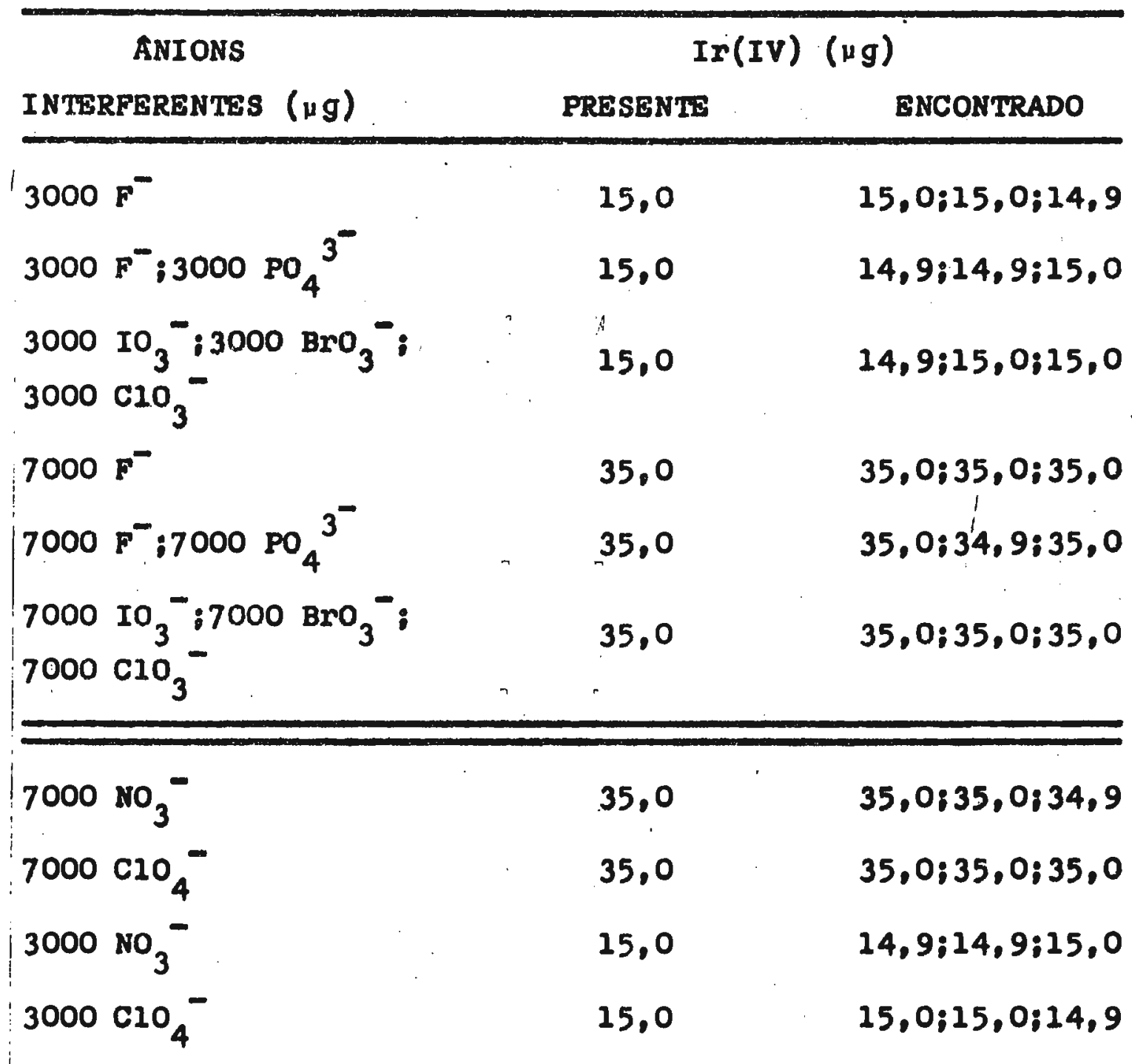

fase orgânica foi transferida diretamente para um balão de $10 \mathrm{ml}$ e completado con cloroformio, sendo uma parte usado para a lavagem. Os resultados aparecem na Tabela XI. 
TABELA XI .

Bstudo do Coeficiente de Extração

$$
\operatorname{Ir}(\mathrm{IV}) \mu \mathrm{g} / \mathrm{mI}
$$

\begin{tabular}{lcrr}
\hline $\begin{array}{c}\text { VALORES OBTIDOS } \\
\begin{array}{c}\text { PROCEDIMENTO } \\
\text { NORMAL }\end{array}\end{array}$ & $\begin{array}{c}\text { VALORES OBTIDOS NAS } \\
\text { EXPERIENCIAS }\end{array}$ & $\begin{array}{c}\text { VALORES } \\
\text { MEDIOS }\end{array}$ & $\begin{array}{c}\text { \% DE } \\
\text { EXTRAÇAOO }\end{array}$ \\
\hline 5,0 & 4,$9 ; 4,9 ; 4,8 ; 4,8$ & 4,9 & 98,0 \\
15,0 & 14,$9 ; 14,9 ; 14,9 ; 15,0$ & 34,9 & 99,3 \\
35,0 & 34,$8 ; 34,9 ; 35,0 ; 34,9$ & 34,9 & 99,7 \\
50,0 & 49,$8 ; 49,9 ; 49,9 ; 49,9$ & 49,9 & 99,7 \\
\hline
\end{tabular}

IIIf. Estudo da precisão do método.

Executaram-se duas sêries de quinze determinações in dependentes, sendo a concentração de Ir(IV) em cada uma dessas séries, respectivamente, $15,0 \mu \mathrm{g} / \mathrm{ml}$ e $35,0 \mu \mathrm{g} / \mathrm{ml}$.

Os dados obtidos expressos em valor de absorbância das soluções, em sua diluição final, estão reunidos na Tabela XII.

Convertendo-se a média e os correspondentes limites de confiança em têrmos de microgramas de iridio encontrado pa$r a$ as amostras, obtém-se, respectivamente, os valores de $14,9 \pm 0,05 \mu \mathrm{g}$ e $34,8 \pm 0,06 \mu \mathrm{g}$. 
Concluimos, portanto, que una determinação isolada proporcionará um resultado dentro de tais limites, com proba bilidade de êrro de $5 \%$.

\section{TABELA XII}

Estudo da Precisão do Método

Medidas de Absorbância em $\lambda=494 \mathrm{~m}_{\mu}$

$\operatorname{Ir}$ (IV) PRESENTE $15,0 \mu \mathrm{g} / \mathrm{ml}$

Ir(IV) PRESENTE $35,0 \mu \mathrm{g} / \mathrm{ml}$

$\begin{array}{llllll}0,294 & 0,291 & 0,297 & 0,686 & 0,683 & 0,684\end{array}$

$\begin{array}{llllll}0,290 & 0,295 & 0,293 & 0,684 & 0,684 & 0,682\end{array}$

$\begin{array}{llllll}0,292 & 0,293 & 0,294 & 0,683 & 0,680 & 0,682\end{array}$

$\begin{array}{llllll}0,293 & 0,290 & 0,292 & 0,685 & 0,680 & 0,682\end{array}$

$\begin{array}{llllll}0,291 & 0,294 & 0,290 & 0,684 & 0,681 & 0,682\end{array}$

Média $=0,292$

Média $=0,683$

Desvio padrão $=0,0017$

Desvio padrão $=0,0020$

L.C. $0,95=0,0010 \quad$ L.C.0,95 $=0,0012$

IIIg. Procedimento.

A solução de partida, com um volume de $2,0 \mathrm{ml}$ contida num funil de separação de cêrca de $20 \mathrm{ml}$ de capacidade, modêlo "pêra" (a fim de conseguir melhor separação das fases ao se aplicarem movimentos circulares ao mesmo), adiciona-se 
$0,3 \mathrm{ml}$ de $\mathrm{HCl} 12 \mathrm{~N}, 0,2 \mathrm{ml}$ de solução de ácido ascórbico a $0,5 \%$ recentemente preparada, $1,0 \mathrm{ml}$ de solução de trí fenil n-propil fosfônio a $5 \%, 1 \mathrm{ml}$ de clorofórmio e agi ta-se. Por movimentos circulares feitos com o funil, de canta-se a parte orgânica, a qual é retirada do funil e a solução remanescente é lavada com três porções de clorofórmio de $1 \mathrm{ml}$ cada. Após isso, adiciona-se à solução, no funil, 1,0 ml de água de cloro (saturada), 0, 3 $\mathrm{ml}$ de $\mathrm{HCl} 12 \mathrm{~N}, 1,0 \mathrm{ml}$ de solução de cloreto de trifenil n-propil fosfônio a 5\%, $1 \mathrm{ml}$ de cloroformio e agita-se. Decanta-se da maneira acima descrita e transfere-se o extrato orgânico a um balão de $10 \mathrm{ml}$ de capacidade. La va-se a solução no funil com três porções de clorofórmio de $1 \mathrm{ml}$ cada transferindo-as ao balão. Ajusta-se o volume do balão com cloroformio e efetua-se a medida espectrofotométrica em $494 \mathrm{~m} \mu$. No caso de se perceber ligeira turvação no extrato orgânico, devido ao eventual arraste de algumas gôtas da solução aquosa, apbs completar-se o volume do balão volumétrico com clorofór mio, adiciona-se ao mesmo pequena porção de sulfato de sódio anidro e agita-se. Em seguida, efetua-se … medida espectrofotometrica.

IV. DETERMI NAÇÃO ESPECTROFOTOME TRICA DE RODIO

IVa. Estudos preliminares.

Após a separação de $\operatorname{Ir}($ IV) e sua determinação, passou-se a estudar a possibilidade de se tentar a 
extração de $R h($ III) que restou em solução. Para isso, tornou-se necessário a introdução de outro complexante, Como já havia sido tentado sem êxito o uso de lons bro meto ( $\mathrm{pág.} \mathrm{27),} \mathrm{iniciou-se} \mathrm{um} \mathrm{estudo} \mathrm{visando} \mathrm{a} \mathrm{utiliza}$ ção de lons tiocianato ou azoteto.

Inicialmente, efetuou-se um estudo sistemati co da extratibilidade dos complexos de $\mathrm{Rh}$ (III)com fons tiocianato e azoteto, precipitados com lons trifenil n-propil fosfônio. Os resultados encontram-se na Tabe la XIII sendo o critério de avaliação idêntico ao utilizado nas Tabelas I e II.

IVb. Espectro de absorção, lei de Beer e diagrama de Ringbom.

Como se nota pelos dados na Tabela XIII, o tiocianato-complexo de $\mathrm{Rh}$ (III) mostrou btima extratibi lidade em cloroformio e nessas condições foi obtido ex trato orgânico amarelo. Como se percebe pela Figura 4 - espectro não se apresenta favorável à escôlha de uma região com finalidades de medida.

Por outro lado, o espectro de absorção do ex trato orgânico obtido pela extração em clorofórmio do azoteto-complexo de $\mathrm{Rh}$ (III), precipitado com lons trifenil n-propil fosfónio, mostrou duas bandas, uma con máximo pouco acentuado na região de 404-408 $\mathrm{m}_{\mu}$ e outra com máximo melhor definido na região de $482-488 \mathrm{m \mu}$, co. mo se vê na figura 5. 
TABELA XIII

Extração de sais de Trifenil n-Propil Fosfônio de Pseudo-Halogeno Complexos de $\mathrm{Rh}$ (III)

\begin{tabular}{|c|c|c|}
\hline SOLVENTES & $\begin{array}{l}\text { TIOCIANATO } \\
\text { COMPLEXO }\end{array}$ & $\begin{array}{l}\text { AZOTETO } \\
\text { COMPLEXO }\end{array}$ \\
\hline Alcool n-butilico & + & 0 \\
\hline Alcool i-butilico & $t$ & 0 \\
\hline Alcool n-pentilico & $t$ & + \\
\hline Alcool i-pentilico & $t$ & + \\
\hline Ciclohexanol & $t$ & $t$ \\
\hline 2-metil ciclohexanol & ++ & $t$ \\
\hline Acetato de etila & + & 0 \\
\hline Acetato de $n$-propila & 0 & 0 \\
\hline Acetato de n-butila & $t$ & 0 \\
\hline Acetato de i-butila & $t$ & 0 \\
\hline Acetato de $n$-pentila & 0 & 0 \\
\hline Acetato de i-pentila & + & 0 \\
\hline Fosfato de tri n-butila & $t$ & + \\
\hline Metil n-propil cetona & + & + \\
\hline Metil i-propil cetona & + & + \\
\hline Metil i-butil cetona & + & + \\
\hline Metil n-pentil cetona & ++ & + \\
\hline Metil i-pentil cetona & ++ & + \\
\hline Metil hexil cetona & ++ & 0 \\
\hline Diisobutil cetona & 0 & 0 \\
\hline Ciclohexanona & ++ & + \\
\hline 2-metil ciclohexanona & ++ & + \\
\hline Anisol & 0 & 0 \\
\hline Fenetol & + & 0 \\
\hline Benzeno & 0 & 0 \\
\hline Tolueno & 0 & 0 \\
\hline Cloroformio & $++t$ & +++ \\
\hline
\end{tabular}




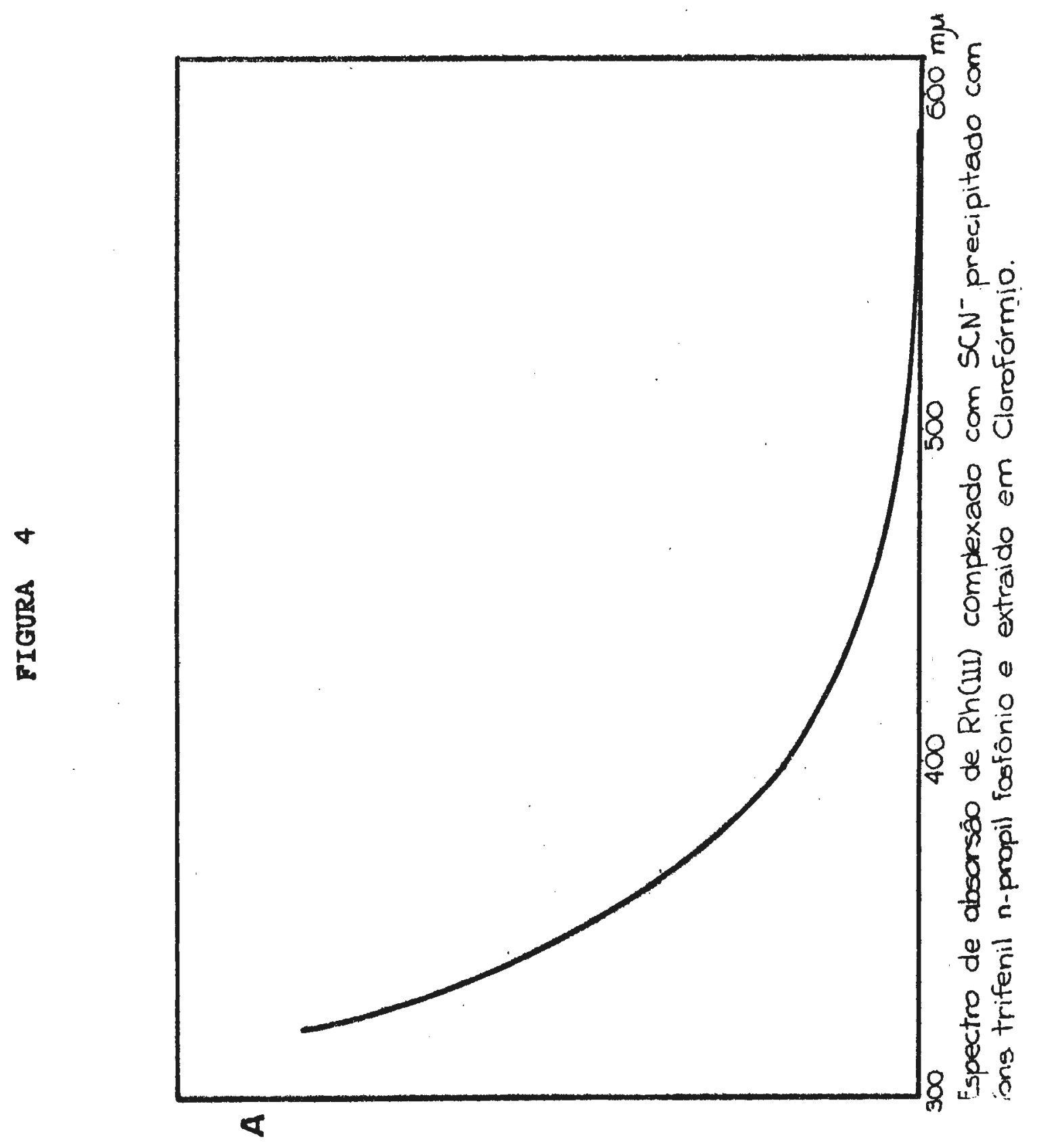




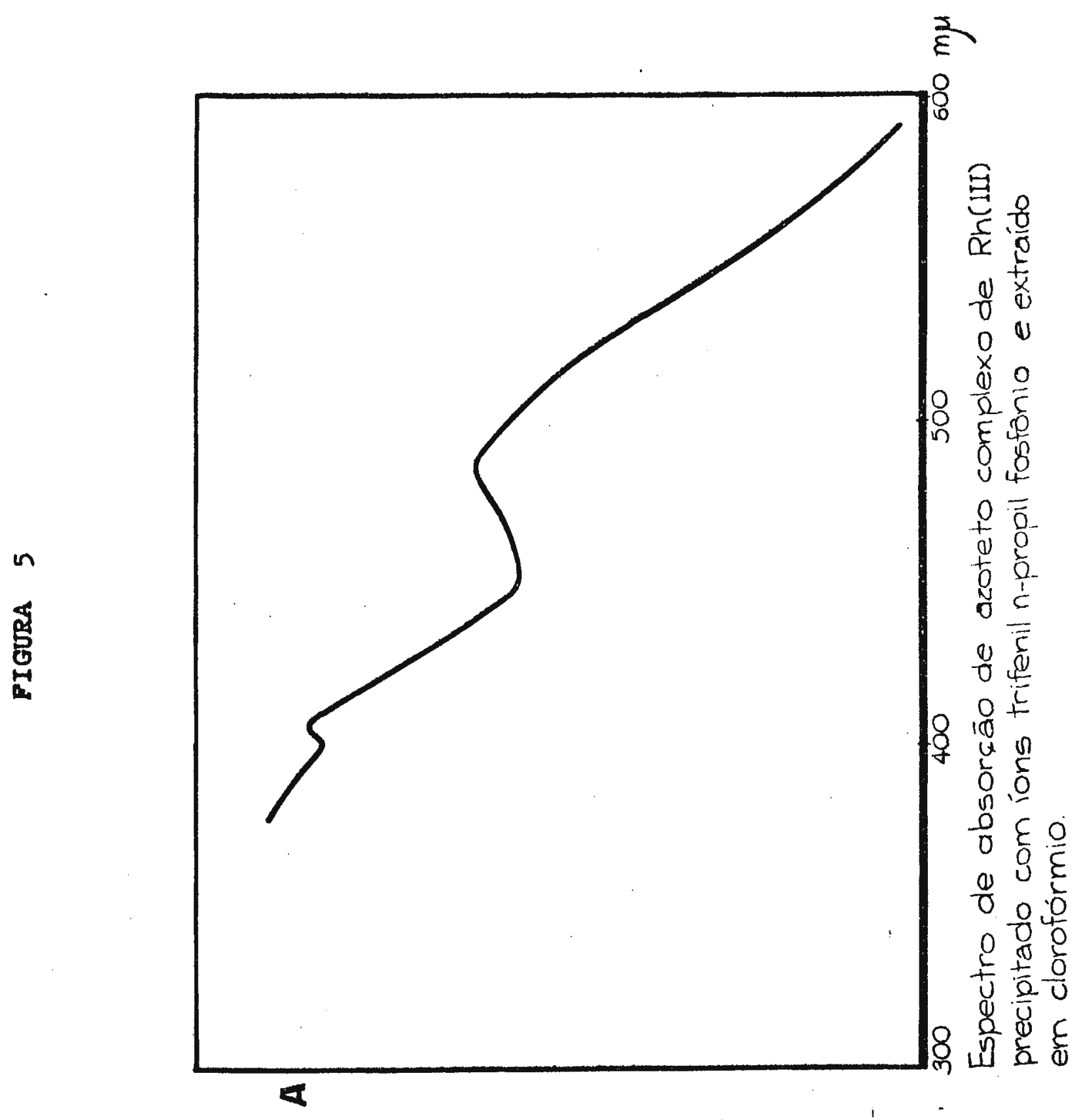


Verificou-se obediência à lei de Beer nas regiões dos dois máximos citados, no intervalo de 10,0 a $70,0 \mu \mathrm{g} / \mathrm{ml}$ de $\mathrm{Rh}(\mathrm{III})$ na diluição final (Figura 6).

o diagrama de Ringbom mostrou que a região de concentração btima de trabalho situa-se no intervalo de 20,0 a $60,0 \mu \mathrm{g} / \mathrm{ml}$ de $\mathrm{Rh}$ (III) na diluição final, na região de 404-408 $\mathrm{m \mu}$ e de 30,0 a $60,0 \mu \mathrm{g} / \mathrm{ml}$ de $\mathrm{Rh}$ (III na diluição final, na região de $482-488 m \mu$. Podemos obser var fal fato na Figura 7.

Observou-se que o desenvolvimento da coloracão vermel ha em solução aquosa se dá no intervalo de $\mathrm{pH}$ 5,0-8,0 e a mesma é estável por mais de duas horas.

IVc. Determinação Ir-Rh.

Obedecendo-se 0 procedimento estabelecido para as determinações de irídio e ródio (pág.48), obtiveram-se bons resultados, os quais encontram-se reunidps na Tabela XIV.

Com relação a inferferentes, certos metais que não interferiam na determinação de $\operatorname{Ir}(I V), 0$ fazem na de terminação de $R h$ (III), tais como; $C o(I I), N i(I I), C u(I I)$, etc. Quanto a $\mathrm{Fe}$ (III), sua interferência foi evitada a dicionando-se a solução $0,1 \mathrm{ml}$ de solução de fluoreto de sodio $1,5 \mathrm{M}$. 


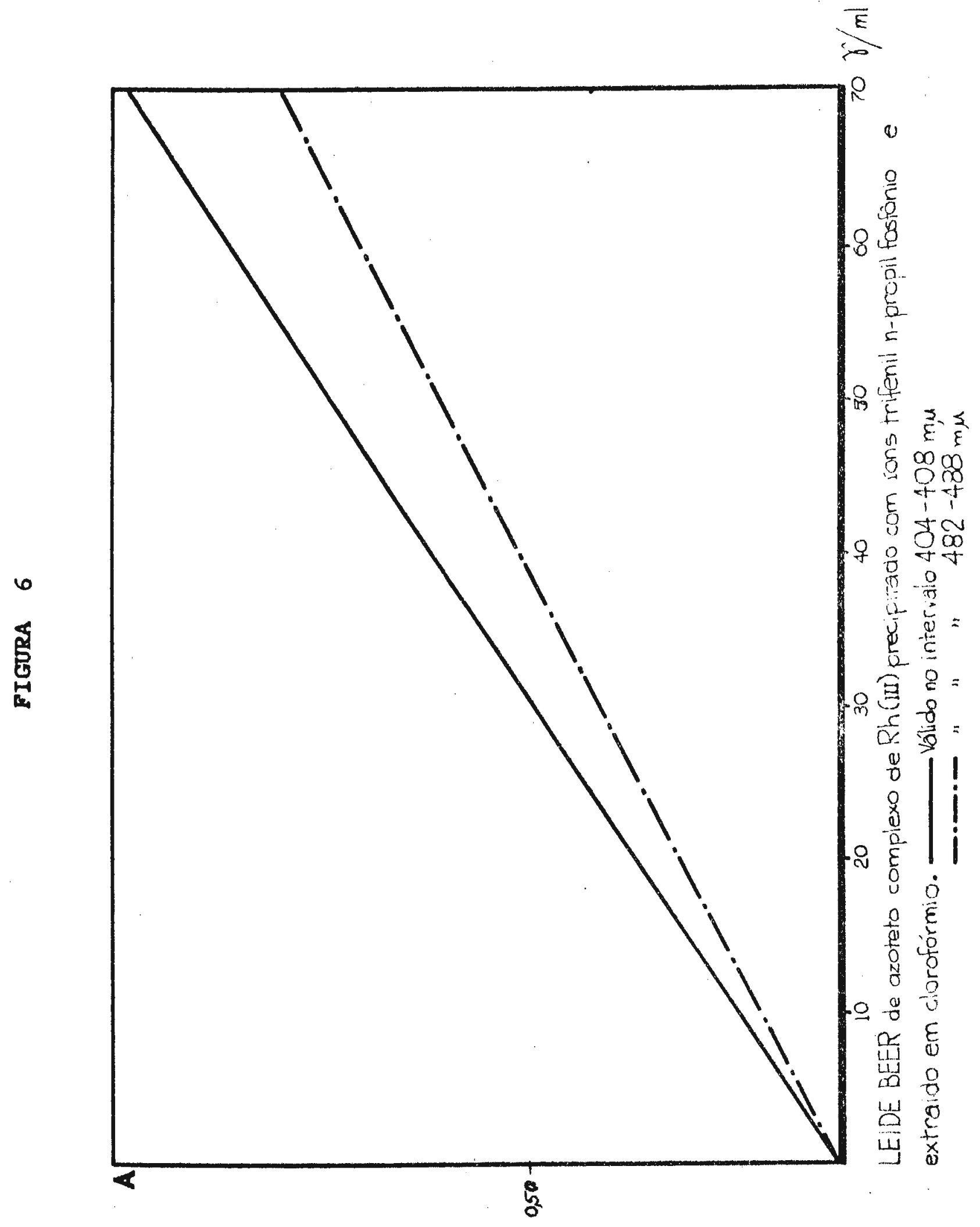




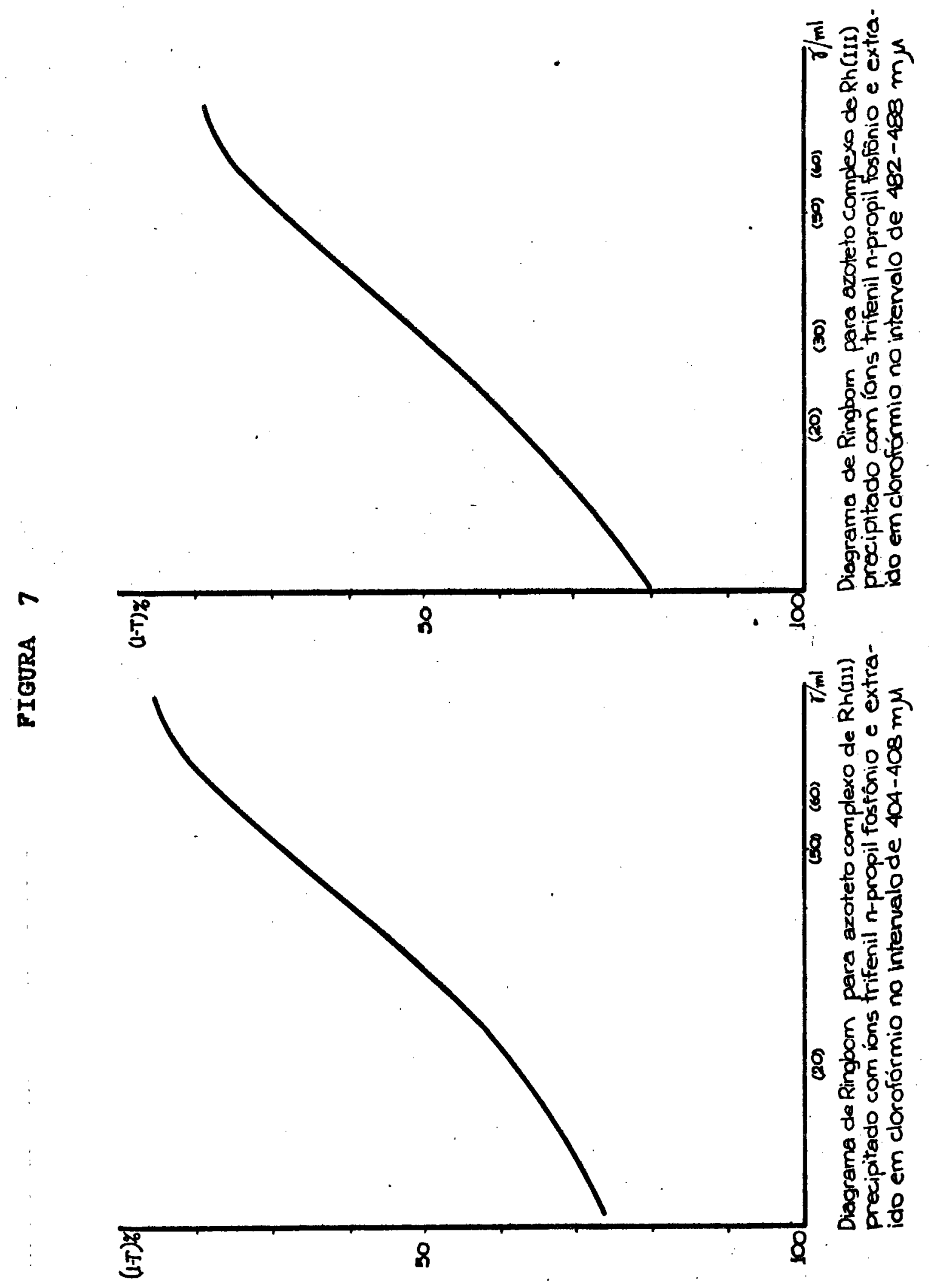


TABELA XIV

Separação e Determinação de $\operatorname{Ir}($ IV) e $R h$ (III)

de Misturas em Solução e na Presença de

Ions Metálicos

\begin{tabular}{|c|c|c|}
\hline QUANTIDADES EM MISTURA $(\mu g)$ & $\begin{array}{l}\text { QUANTIDADES } \\
\operatorname{Ir}(\mathrm{IV})\end{array}$ & $\begin{array}{r}\text { ENCONTRADAS }(\mu g) \\
\operatorname{Rh}(I I I)\end{array}$ \\
\hline $20,0 \operatorname{Ir}(\mathrm{IV}) ; 30,0 \mathrm{Rh}(\mathrm{III})$ & 20,$0 ; 20,0$ & 30,$2 ; 30,1$ \\
\hline $15,0 \operatorname{Ir}(\mathrm{IV}) ; 50,0 \mathrm{Rh}(\mathrm{III})$ & 14,$9 ; 15,0$ & 49,$8 ; 50,0$ \\
\hline $35,0 \operatorname{Ir}(\mathrm{IV}) ; 20,0 \mathrm{Rh}(\mathrm{III})$ & 35,$0 ; 34,9$ & 19,$8 ; 20,1$ \\
\hline $\begin{array}{l}25,0 \mathrm{Ir}(\mathrm{IV}) ; 35,0 \mathrm{Rh}(\mathrm{III}) \\
7000 \mathrm{Os}(\mathrm{IV})\end{array}$ & 24,$9 ; 24,9$ & 34,$9 ; 35,0$ \\
\hline $\begin{array}{l}20,0 \operatorname{Ir}(\mathrm{IV}): 30,0 \mathrm{Rh}(\mathrm{III}) ; \\
7000 \mathrm{Os}(\mathrm{IV}): 7000 \mathrm{Pd}(\mathrm{II})\end{array}$ & 19,$9 ; 20,1$ & 29,$9 ; 30,0$ \\
\hline
\end{tabular}

IVd. Eficiência da extração.

o coeficiente de extração foi avaliado numa faixa de concentração de 10,0 a $70,0 \mu \mathrm{g} / \mathrm{ml}$ de $\mathrm{Rh}$ (III) na diluição final, 0 . que pode ser visto na Tabela Xv. 
TABELA XV

Estudo do Coeficiente de Extração de Azoteto

Complexo de $R h(I I I)$ a 404-408 $m \mu$

\begin{tabular}{|c|c|c|c|}
\hline $\begin{array}{l}\text { VALORES OBTIDOS } \\
\text { NO PROCEDIMENTO } \\
\text { NORMAL }\end{array}$ & $\begin{array}{l}\mathrm{Rh}(\mathrm{III}) \mu \mathrm{g} / \mathrm{ml} \\
\text { VALORES OBTIDOS NOS } \\
\text { EXPERIMENTOS }\end{array}$ & $\begin{array}{r}\text { VALORES } \\
\text { MEDIOS }\end{array}$ & $\begin{array}{c}\% \text { DE } \\
\text { EXTRAÇÃO }\end{array}$ \\
\hline 10,0 & 9,$7 ; 9,0 ; 9,5 ; 9,7 ; 9,6$ & 9,6 & $96, c$ \\
\hline 35,0 & 34,$5 ; 34,9 ; 34,7 ; 34,7 ; 34,8$ & 34.7 & 99,1 \\
\hline 70,0 & 69,$8 ; 69,7 ; 69,8 ; 69,8 ; 69,9$ & 69,8 & 99,7 \\
\hline
\end{tabular}

IVe. Estudo da precisão do método.

Executaram-se duas séries de quinze determinações in dependentes, com as duas serries contendo $\mathrm{R} h$ (III), respectivamen te, com 20,0 $\mu \mathrm{g} / \mathrm{mI}$ e $50,0 \mu \mathrm{g} / \mathrm{ml}$.

Os dados obtidos, expressos em valor de absorbância das soluções, em sua diluição final, estão reunidos na Tabela XVI.

Convertendo-se a média e os correspondentes limites de confiança em têrmos de microgramas de ródio encontrados para as duas séries, obtem-se os valores, respectivamente, de $19,6 \pm$ $0,11 . \mu \mathrm{g}$ e $49,7 \pm 0,11 \mu \mathrm{g}$. 
Pode-se concluir, portanto, com probabilidade de êr ro de apenas $5 \%$, que uma determinação isolada proporcionará un resultado dentro de tais limites.

TABELA XVI

Estudo da Precisão do Método

Medidas de Absorbância em $\lambda=404-408 \mathrm{~m} \mu$

\begin{tabular}{|c|c|c|c|c|c|}
\hline 0,221 & 0,217 & 0,215 & 0,553 & 0.548 & 0,547 \\
\hline 0,220 & 0,217 & 0,215 & 0,550 & 0,547 & 0,548 \\
\hline 0,218 & 0,219 & 0,217 & 0,548 & 0,546 & 0,549 \\
\hline 0,220 & 0,216 & 0,215 & 0.547 & 0,548 & 0.546 \\
\hline 0,220 & 0,215 & 0,215 & 0,549 & 0,551 & 0.545 \\
\hline \multicolumn{3}{|c|}{ Média $=0,217$} & \multicolumn{3}{|c|}{ Média $=0,548$} \\
\hline \multicolumn{3}{|c|}{ Desvio Padrão $=0,0022$} & \multicolumn{3}{|c|}{ Desvio Padrão $=0,0022$} \\
\hline \multicolumn{3}{|c|}{ L.C. $0.95=0,0012$} & \multicolumn{3}{|c|}{ L.C.C. $0,95=0,0012$} \\
\hline
\end{tabular}


IVf. Procedimento.

Após a separação e consequente determinação de Ir(IV) (pág. 36), ao funil contendo o cloro-comple xo de $R h$ (III), adiciona-se $0,5 \mathrm{ml}$ de solução de azote to de sodio 2,5M, agita-se e expõe-se o mesmo a ação de uma lâmpada $\quad$ G.E. "Infravermelho" -250W. A solu u ção avermelhece aos poucos e após 20 minutos de aquecimento (cuja temperatura fica entre 90 e $100^{\circ} \mathrm{C}$ ), dei xa-se esfriar e adiciona-se $2,0 \mathrm{ml}$ de solução de trifenil n-propil fosfônio a $15 \%$, agita-se e extrai-se o precipitado com $2 \mathrm{ml}$ de clorofórmio. o funil é poste riormente lavado com três porções de clorofórmio de $1 \mathrm{ml}$ cada. 0 extrato colorido e as porções de lavagem são transferidos a um balão de $10 \mathrm{ml}$ e efetuamse a leitura espectrofotométrica.

IVg. Esquema de separação.

Em função dos resultados obtidos, elaborouse um esquema de separação que segue: 

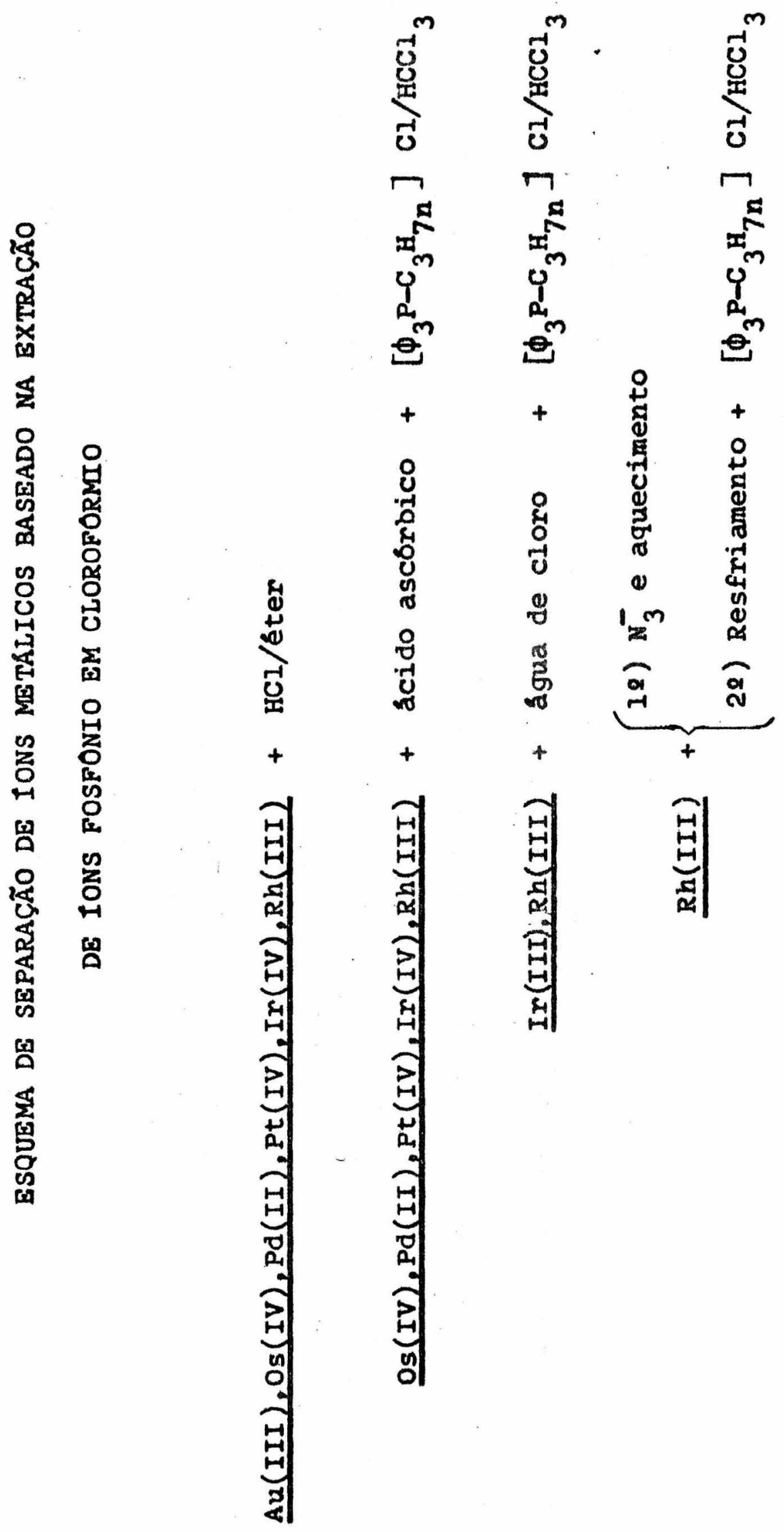


\section{NATUREZA DOS COMPOSTOS}

A fim de obter esclarecimentos quanto a nature za dos compostos extraidos, procuroumse preparar o sal correspondente ao cloro-complexo de irldio, bem como o do azoteto-complexo de r6́dio.

A preparação descrita mais adiante, em suas di ferentes fases ( $p a ̊ g .72$ ) conduziu a dois compostos que, apbs analisados, mostraram corresponder as formulas $\left[\phi_{3} \mathrm{P}^{-\mathrm{C}_{3} \mathrm{H}_{7 \mathrm{n}}}\right]_{2}\left[\mathrm{IrCl}_{6}\right]$ e $\left[\phi_{3}{\mathrm{P}-\mathrm{C}_{3} \mathrm{H}_{7 \mathrm{n}}}_{3}\left[\mathrm{Rh}\left(\mathrm{N}_{3}\right)_{6}\right]\right.$. respectivamente.

Os dois compostos, dissolvidos em cloroformio, apresentaram espectro de absorção coincidente com o observado na aplicação dos metodos descritos (Figuras 1 e 5).

VI. SEPARAÇÃO DE OS(IV) DA SOLUÇÃO INICIAL

vIa. Considerações Preliminares.

o estudo visou a possibilidade de se conseguir determinar os(IV), prèviamente separado da solução inicial e contido no extrato cloroformico, juntamente com os sais de trifenil n-propil fosfônio dos cloromcomplexos de $\operatorname{Pt}(I V)$ e $\operatorname{Pd}(I I)$ (pág. 72).

Assim sendo, o primeiro passo foi o estudo da 
possibilidade de se fazer com que os Ions cloro-comple xos de $\mathrm{Pt}(\mathrm{IV}), \mathrm{Pd}(\mathrm{II})$ e Os(IV) retornassem a fase aquosa. para isto, pensou-se em agitar o extrato orgânico com uma solução de um ânion que, juntamente com lons fosfönio, seria extraldo em cloroformio, a fim de promover a volta dos cloro-complexos acima citados a solução aquosa.

Para êsse fim tentou-se o emprêgo de lons nitrato, tiocianato e perclorato. Experimentos mostraram que apenas lons perclorato fornecem resultados quantitativos, ou seja, lons perclorato mostram grande facilidade em reter lons fosfônio na fase orgânica.

Por outro lado, a agitação do extrato cloroformico com vários solventes a fim de se tentar a passagem de alguma espécie do cloroformio ao solvente usado, não forneceu bons resultados. Assim o uso de lons perclorato tornou-se necessário como primeiro passo para a separação dos lons cloro-complexos. Portanto, após agitação do extrato orgânico com solução de lons perclorato, a parte aquosa (contendo os cloro-complexos de Os(IV), Pd(II), Pt(IV) e $\mathrm{ClO}_{4}^{-}$) foi transferida para um tubo de ensaio. A partir dessa situação, o estudo visou a extra ção e determinação de $0 s(I V)$ da solução aquosa.

o trabalho foi iniciado por um estudo sistemático da extração dos sais de fosfônio dos cloro-complexos dêsses metais nos mesmos solventes utilizados na Tabela XVI; além dêsses, incluiu-se tetracloreto de carbono e metil n-butil cetona. Verificou-se não ser possi- 
vel separar os(IV) de Pt(IV) e Pd(II), por extração em solventes orgânicos de seus sais de fosfônio (trifenil n-propil e trifenil i-propil).

Idêntico estudo sistemático foi efetuado usan do-se outros complexantes: Ions brometo, azoteto, iodeto e tiocianato. Para cada um dos complexantes usados, efetuou-se o mesmo estudo sistemático con relação aos solventes jă citados e com ambos os sajs de fosfônio (trifenil n-propil e trifenil i-propil), verificando-se não ser possivel a separação de Os(IV)de Pd(II)e Pt(IV). Essa impossibilidade foi verificada tanto com relação a extração dos sais de fọsfônio de os(IV), para separáłilo de $P t(I V)$ e $P d(I I)$ quanto às extrações dos sais de fosfônio de Pt(IV) e Pd(II), com o objettivo de deixar isolado o de Os(IV).

Diante da impossibilidade de efetuar essa separação de maneira quantitativa, tentoúse, a seguir, a extração em solventes orgânicos de os(IV), sem a adição de sais de fosfônio. Dados da literatura $(49,50)$ mostraram não ser simples essa separação.

o trabalho teve prosseguimento com a realização de um estudo sistematico da extração em solventes orgânicos dos halogeno. e pseudo-halogeno complexos dos metais em questão: Os(IV), Pt(IV) e Pd(II), com o emprê go dos solventes citados há pouco. 
Apos êsse estudo, verificou-se haver a possibilidade de se separar os(IV) da mistura, pela extração dos tiocianato-complexos de Pt(IV) e Pd(II), ficando Os(IV) em solução aquosa, sendo essa extração efetuada por meio de metil n-butil cetona.

Após a adição de lons tiocianato à solução, tornou-se necessário aguardar cêrca de uma hora antes de se adicionar o solvente e iniciar-se a operação de extração. o fenômeno é devido ao fato de que a formação de tiocianato-complexo de Pt(IV), a partir de cloro complexo, es cineticamente desfavorável.

SENISE A PITOMBO (41) verificaram que a luz catalisa a troca de cloro por tiocianato na formação do complexo, porém esta técnica não pode ser aplicada no presente caso pois Pt(IV) encontra-se como interferente em relação a os(IV), ou seja, em quantidades consideráveis $e$, nessas condições, a catálise torna-se de baixo rendimento. Experimentos mostraram, por outro lado, que um aquecimento da solução contendo os cloro-complexos, após adição de lons tiocianato, tambêm não levou a bons resultados, pois havia, posteriormente, extração de uma parte de os(IV).

A solução para o problema foi encontrada pela adição de um redutor. Segundo TAUBE ${ }^{(51)}$, a substituição de átomos de cloro por outros átomos, no cloro-complexo de Pt(IV), es catalisada pela presença de redutores na solução e dificultada pela de oxidantes. Dos re 
dutores empregados, o que apresentou melhores resultados foi $\circ \operatorname{sn}(I I)$.

Após agitação đa solução inicial contendo fons tiocianato e algumas gôtas de solução de $s n(I I)$, adiciona-se metil n-butil cetona, conseguindóse extração quan titativa de Pt(IV) e Pd(II). A seguir, com a solução aquosa remanescente, contendo Os(IV), efetua-se uma medi da espectrofotométrica.

VIb. Espectro de absorção, lei de Beer e diagrama de Ringbom.

- espectro de absorção da solução aquosa de os(IV) contendo lons tiocianato e $\operatorname{sn}$ (II) mostrou ser idêntico ao espectro de uma solução de seu cloro-complexo em/HCl, tudo indicando que o cloromcomplexo de Os(IV) se mantém em solução aquosa em presença de lonṣ tiociana to e $\operatorname{sn}(\mathrm{II})$. 0 espectro de uma solução de $\mathrm{OsCl}_{6}{ }^{--} \mathrm{em}$ HCl. $O_{2} I N$ mostrou banda característica com máximo a $370 \mathrm{~m} \mu$, assim como a solução resultante da separação de $P t(I V)$ e Pd(II) (Figura 8 ).

Verificou-se que a lei de Beer é obedecida no intervalo de 2,0 a $20,0 \mu \mathrm{g} / \mathrm{ml}$ em $O s(I V)$ na diluição $f \underline{i}$ nal (Figura 9).

- diagrama de Ringbom indica como sendo de 5,0 a $17.0 \mathrm{\mu g} / \mathrm{ml}$ a melhor região de medida (Figura 10 ). 


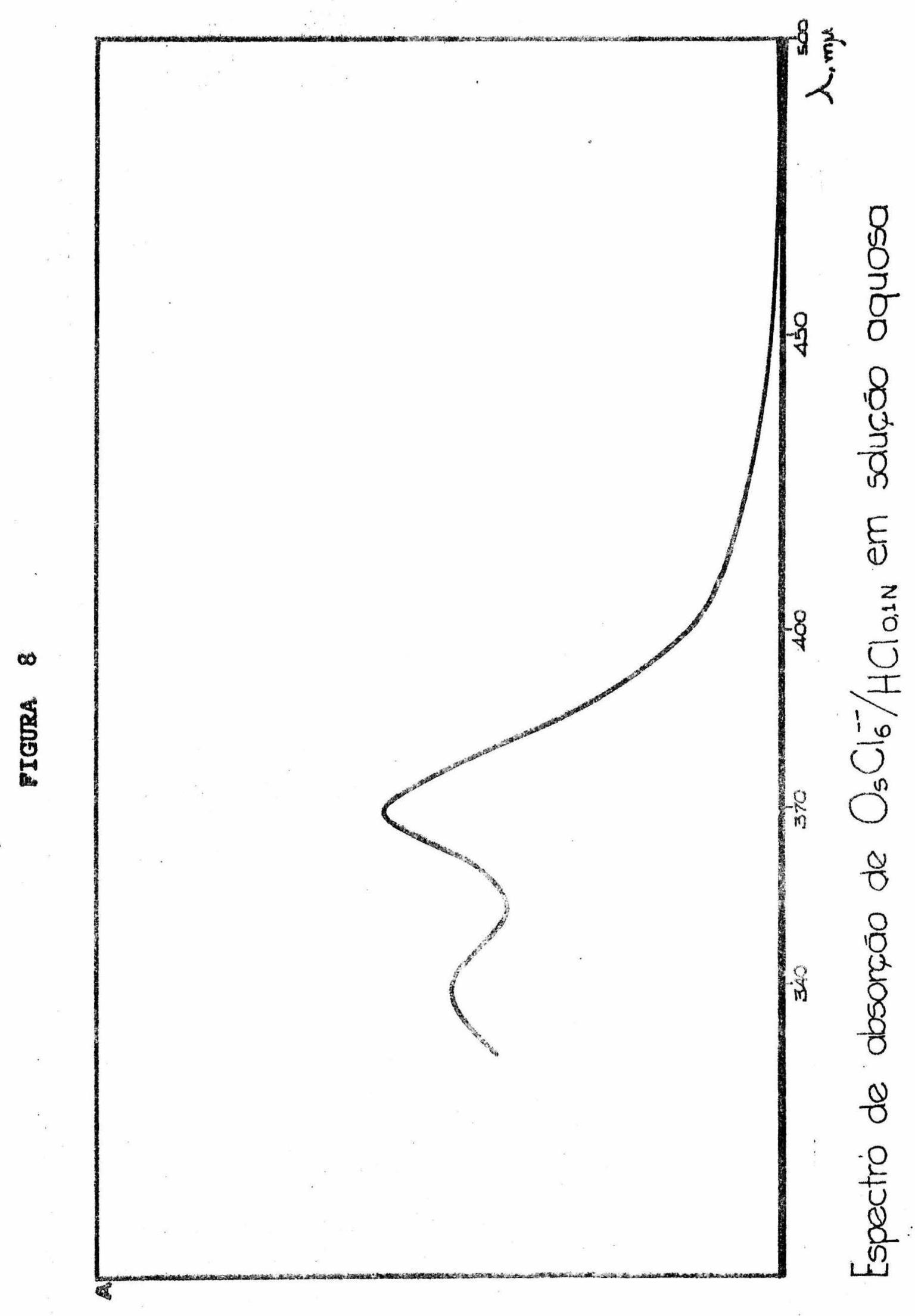




$$
\nabla
$$




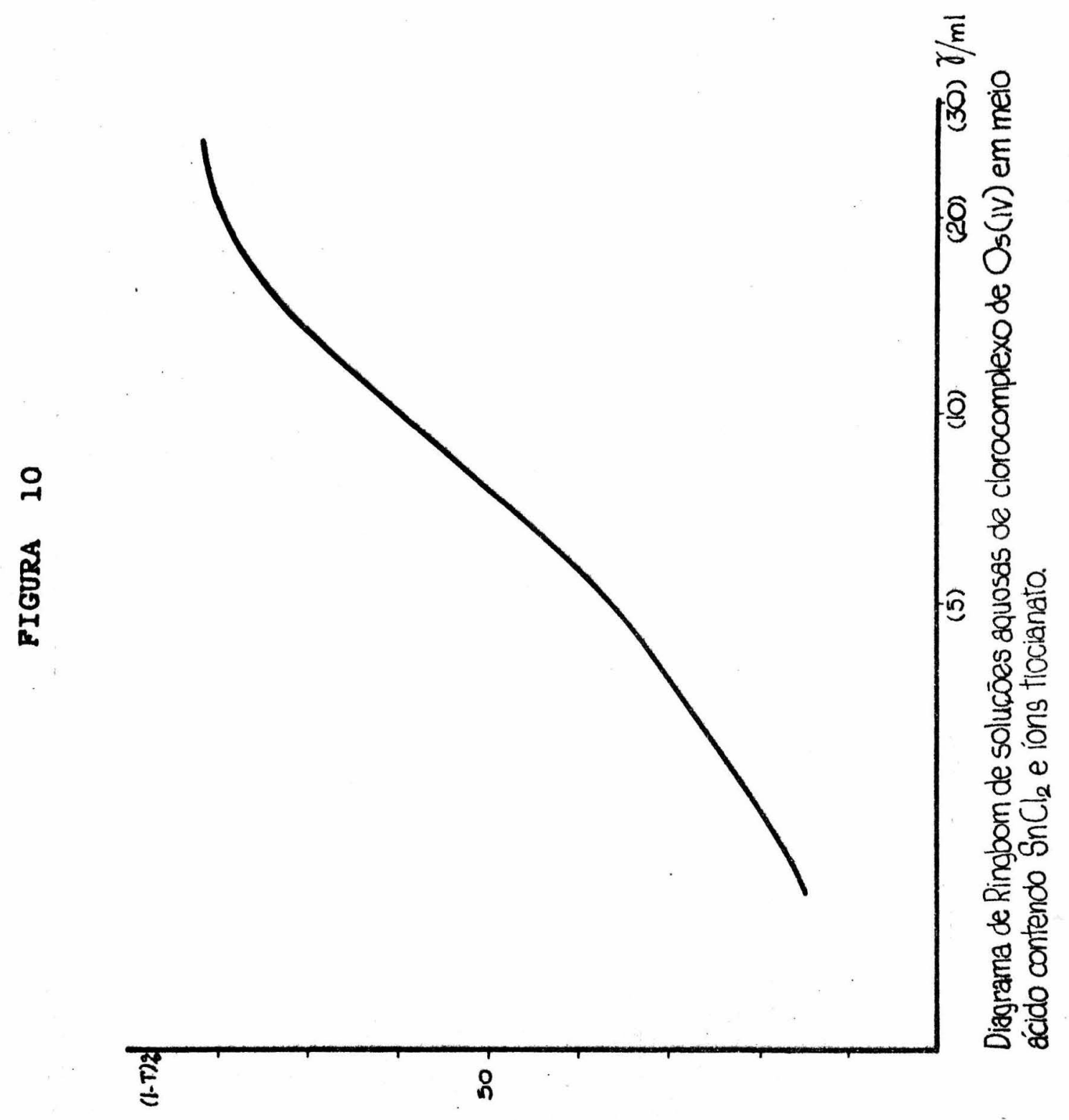


VIc. Separações Os(IV)-Pt(IV) e Pd(II).

Aplicando-se o procedimento estabelecido (pág.60), vá rias separações foram efetuadas; os dados encontram-se na Tabe la XVII.

\section{TABELA XVII}

Separação e Determinação de Os(IV) de suas Mistura com $\operatorname{Pd}(I I)$ e $\mathrm{Pt}(\mathrm{IV})$

IONS INTERFERENTES $(\mu \mathrm{g})$

$$
\text { Os(IV): ( } \mu g)
$$

PRESENTE

ENCONTRADO

\begin{tabular}{lll}
\hline $1000 \mathrm{Pt}(\mathrm{IV}) ; 1000 \mathrm{Pd}(\mathrm{II})$ & 10 & 9,$9 ; 9,8 ; 9,8 ; 9,8$ \\
$2000 \mathrm{Pt}(\mathrm{IV}) ; 2000 \mathrm{Pd}(\mathrm{II})$ & 10 & 9,$7 ; 9,7 ; 9,6 ; 9,5 ;$ \\
& & 9,$7 ; 9,6 ; 9,7 ; 9,8$ \\
$2000 \mathrm{Pt}(\mathrm{IV}) ; 2000 \mathrm{Pd}(\mathrm{II})$ & 20 & 19,$7 ; 19,7 ; 19,6 ; 19,6 ;$ \\
& & 19,$8 ; 19,8 ; 19,7$ \\
$2500 \mathrm{Pt}(\mathrm{IV}) ; 2500 \mathrm{Pd}(\mathrm{II})$ & 20 & 19,$8 ; 19,7 ; 19,7 ; 19,7$
\end{tabular}

A concentração hidrogeniônica na solução ao se iniciar a extração deve ser ao redor de $1,5 \mathrm{M}$. Com concentrações acima de 2,OM, o cloro-complexo de Os(IV) também e extraido. 0 uso de $\mathrm{HCl}$ ao invés de $\mathrm{H}_{2} \mathrm{SO}_{4}$ não mostrou bons resultados haven do, provalvelmente, competição de $\mathrm{Cl}^{-} \mathrm{com} \mathrm{SCN}^{-}$. 
As medidas de absorbância das soluções de os(IV) nessas condições (contendo lons tiocianato e $\mathrm{SnCl}_{2}$ ), coincidiram com as das soluções de $\mathrm{OsCl}_{6}^{--} \mathrm{em}$ HCl $0,1 \mathrm{~N}$, desde que efetuadas até 50 minutos apos inicio da operação. Decorrido êsse tempo, verificou-se que a absorbância cala progressivamente, sendo conservada a forma do espectro de absorção da solução inicial.

Não houve evidência de formação de novas espê cies, por medidas espectrofotometricas nas regiões vis1 vel e ultra-violeta, tudo indicando tratar-se de redu cão lenta e progressiva de Os(IV) a Os(III).

vId. Estudo da precisão do método.

Executaram-se duas séries de quinze determina ções independentes, com as duas sêries contendo os(IV), respectivamente, $10,0 \mu \mathrm{g} / \mathrm{ml}$ e $20,0 \mu \mathrm{g} / \mathrm{ml}$.

Os dados obtidos, expressos em valor de absorbância das soluções, em sua diluição final, estão reu nidos na Tabela XVIII.

Convertendo-se a média e os correspondentes $1 \underline{i}$ mites de confiança em têrmos de microgramas de 6smio en contrados para as duas séries, obtém-se os valores, res pectivamente, de $10,0 \pm 0,04 \mu \mathrm{g}$ e $19,9 \pm 0,04 \mu \mathrm{g}$.

Podemos concluir, portanto, com probabilidade 
de acêrto de $95 \%$, que uma determinação isolada proporcionará um resultado dentro de tais limites.

\section{TABELA XVIII}

Estudo da Precisão do Método

Medidas de Absorbância em $\lambda=370 \mathrm{~m} \mu$

OS(IV) PRESENTE $10,0 \mu \mathrm{g} / \mathrm{ml}$

OS(IV) PRESENTE $20,0 \mu \mathrm{g} / \mathrm{ml}$

\begin{tabular}{llllll}
\hline 0,385 & 0,392 & 0,388 & 0,763 & 0,766 & 0,762 \\
0,382 & 0,384 & 0,386 & 0,768 & 0,766 & 0,765 \\
0,382 & 0,383 & 0,382 & 0,760 & 0,769 & 0,764 \\
0,380 & 0,381 & 0,392 & 0,770 & 0,767 & 0,771 \\
0,390 & 0,385 & 0,385 & 0,767 & 0,770 & 0,768 \\
Média $=0,385$ & & Media $=0,766$ & \\
Desvio padrão $=0,0035$ & Desvio padrão $=0,0032$ \\
L.C.0,95 $=0,0019$ & L.C.0,95 $=0,0017$ & \\
\hline
\end{tabular}

VIe. Procedimento.

o extrato orgânico da separação inicial, contendo os sais de fosfônio dos cloro-complexos de os(IV), Pt(IV) e $\mathrm{Pd}(\mathrm{II})$, E transferido diretamente do funil de separação a um 
tubo de extração de capacidade de $10 \mathrm{ml}$ (com rôlha esmerilhada) e, a êsse extrato com cêrca de $5 \mathrm{ml}$ de volume, adiciona-se $1,0 \mathrm{ml}$ de solução de perclorato de sódio $6 \mathrm{M}$ e agita-se. Após centrifugação, a parte aquosa (superior) \& transferida quantitativamente a outro tubo de ex tração de capacidade igual a $5 \mathrm{ml}$, por meio de uma pipeta ${ }^{(48)}$. A lavagem da parte orgânica se faz por meio de duas porções de $0,5 \mathrm{ml}$ cada, de solução de perclorato de sodio $0,5 \mathrm{M}$ e igualmente transferidos para 0 tubo de extração. A êsse tubo adiciona-se $1,5 \mathrm{ml}$ de $\mathrm{H}_{2} \mathrm{SO}_{4} 2,5 \mathrm{M}$, $1,0 \mathrm{ml}$ de solução de NascN 1,5M, $0,1 \mathrm{ml}$ de solução de $\mathrm{SnCl}_{2}$ a $15 \%$ (em $\mathrm{HCl}$ ), $2 \mathrm{ml}$ de metil n-butil cetona e agi ta-se. Centrifuga-se $e$, com a ajuda de uma pipeta de ex tração (48), elimina-se a parte orgânica contendo $\mathrm{Pt}$ (IV) e Pd(II), restando em solução os(IV). Quando os dois me tais interferentes em questão encontram-se em elevada - quantidade (cêrca de $1000 \mathrm{\mu g}$ cada), torna-se necessário que se agite a solução com $\circ$ solvente, com cêrca de 5 porções de $2 \mathrm{ml}$ cada uma; havendo menores quantidades (cêrca de 100 a $200 \mu \mathrm{g}$ de cada), 3 porções de $2 \mathrm{ml}$ são suficientes.

Após eliminação dos interferentes, à solução aquosa adiciona-se solução de $\mathrm{MnO}_{4}^{-} \mathrm{O}, 5 \mathrm{~N}$ às gôtas até leve excesso;a seguir elimina-se o excesso de permangana to com al gumas gôtas de solução de $\mathrm{snCl}_{2}$ a $15 \%$. Transfe re-se a solução aquosa a um balão de $10 \mathrm{ml}$ e o mesmo e completado com HCl $0,1 \mathrm{~N}$. A determinação e feita por medida espectrofotometrica na fase aquosa a $370 \mathrm{~m}_{\mu}$.

VIf. Esquema de separação. 


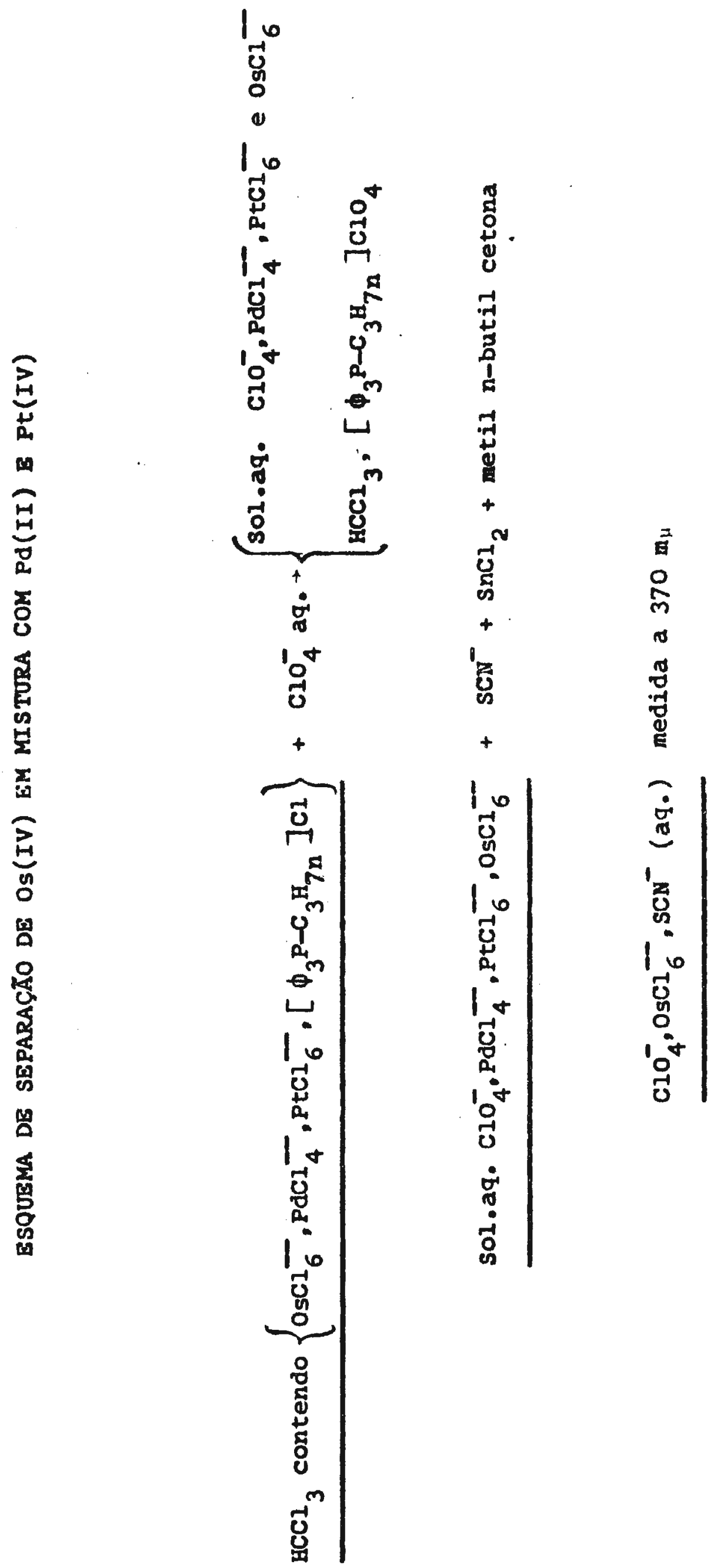


VII. CONSIDERAÇðES FiNAIS

A extratibilidade de sais de fosfonio de trifenil n-propil e trifenil i-propil fosfônio que como foi demonstrado anteriormente

(38) pode proporcionar seletividam de apreciável em muitos casos,foi mais uma vez utilizada em uma separação de grande interêsge analltico. 0 estudo rea lizado confirmou, todavia, a importância que deve ser atrí buida as condlções de trabalho, para se obter exito no apro veitamento desse fenômeno.

Na ampla investigação sistemática procedida nas pesquisas precedentes (38) verificou-se,com apreciável fre quência, que os sais de trifenil n-propil fosfônio de halo geno e pseudo-halogeno complexos de vários fons metálicos são fàcilmente extraíveis no solvente orgânico, en contraposição aos correspondentes compostos contendo o radical isopropila, que permanecem precipitado juntos a fase aquosa.

Tal fato foi constatado apenas parcialmente no que diz respeito aos referidos sais de cloro-complexo de Ir(IV), uma vez que o composto formado com lons trifenil i-propil fosfónio \& em grande parte, mas não totalmente dissolvido em clorofórmio. Essa a razão pela qual se escolneu o cloreto de trifenil n-propil fosfônio como agente precipitante.

Com relação à reduções de $\operatorname{Ir}($ IV) a $\operatorname{Ir}(\mathrm{III})$ que ocorrem quando da permanência de Ir(IV) em presença de cetonas, a que nos referimos a pag. 20, verificou-se que 
as cetonas em questão, isoladas após ređução de $\operatorname{Ir}($ IV) a Ir(III), apresentavam forte caráter oxidante, que atribuímos à presença de peróxidos orgânicos. Mas, com a permanência de soluções de Ir(IV) em contato com as referidas cetonas, em ausência de ar, observou-se a redução de $\operatorname{Ir}($ IV) a Ir(III) bem como que a cetona não apresentava carater oxidante. bem provável que a oxi-redução de $\operatorname{Ir}($ IV) e cetonas (metil n-propil cetona, metil i-propil cetona e 2-metil ciclohexanona) seja idêntica a verificada entre cetonas e lons Mn(III), Co(III) e $v(v)^{(52,53)}$ nas quais os lons mencionados oxidam homoIfticamente a cetona no carbono $\alpha$, com formação de radi cais. Portanto, no nosso caso, presumimos que algo semelhante deva ocorrer, explicando a redução de iridio pelas cetonas, em ausência de ar; posteriormente, os radicais formados iriam reagir com o oxigênio do ar resultando em peróxidos orgânicos.

A separação Ir-Rh por nbs efetuada mostra, co mo se pode aquilatar do relato, grande eficiência e vantagens sôbre outros processos até agora elaborados. Essas vantagens se refletem, não sòmente com relação a simplicidade da execucãa,como também quanto à possibili dade de se aplicar o método em várias condições nas quais outros falham.

Assim, um método análogo ao nosso, estudado por NEEB, baseado na extração em clorofórmio de clorocomplexo de $\operatorname{Ir}($ IV) precipitado com lons tetrafenilfosfônio (36) mostra uma limitação dada pela concentração 
dos reagentes e pela acidez do meio (no nosso caso, não há impedimento com relação a concentração do sal de fos fônio e a faixa mais favorável de acidez é considerável) Por outro lado, o referido método coloca as interferên cias de fons nitrato, perclorato e sulfito como intrans poniveis. Conseguimos contornar a interferência de sul fito, pela oxidação a sulfato e o fato de utilizarmos um sal de fosfônio mais solkvel que cloreto de tetrafenilfosfônio, apresenta-se como vantagem porque possibilita o uso de uma concentração maior de lons fosfônio, havendo, com isso, precipitação e extração de nitrato, perclorato além da de Ir(IV). Com relação às interferências de $\mathrm{Pt}$ (IV) e $\operatorname{Pd}(\mathrm{II})$ que, no trabalho de NEEB não foram objeto de estudo, no nosso esquema são eliminados prèviamente por extração dos seus sais de fosfônio em cloroformio, mantendo-se o irldio na forma de $\operatorname{Ir}($ III), como foi visto no procedimento. Nosso método, inclusive, apresenta uma margem de êrro menor do que a consegui da pelo autor em questão. Or espectro de absorção do ex trato orgânico conseguido por NEEB ê praticamente idêntico ao obtido por nós.

Por outro lado, com relação a determinação de Ir(IV), o processo por nós elaborado apresenta consideráveis vantagens sôbre os já existentes métodos espectrofotometricos pois a maioria dêstes tem sua precisão dependente enormemente da variação da fôrça iônica do meio, de pequenas variações do $\mathrm{pH}$, do tempo de repouso da solução a ser medida, etc. Assim, o método de AYRES 
e BOLLETER, pelo uso do cristal leuco violeta $(54)$ depen de pronunciadamente das condições da s.olução, da mesma maneira que o método do brometo de estanho II (55). Con siderado por BEAMISH como um dos melhores métodos de determinação de $\operatorname{Ir}(I V)(56)$, o de AYREs e QUICK se baseia na produção de coloração plrpura pela fervura da solução com mistura de acidos nitrico, perclbrico e fosforico (57) todavia essa coloração depende da concentração dos ácidos empregados (58). Um método similar a êsse, pelo uso de Ce(IV) (59) não melhorou muito a determinação. Ou tros métodos, pelo uso de p-nitrosodimetilanilina $(60)$ e p-dianisidina (61) mostraram-se pouco precisos, inclusi ve vulneráveis a interferências de ácidos não voláteis. A determinação de iridio após extração de uma solução em mistura com ródio, com fosfato de tri n-butila não é recomendável pois a extração e morosa ${ }^{(62)}$.

Com relação à determinação do ródio, após sepa ração do irídio, alguns dos métodos existentes poderiam seraplicados (22) como o que se baseia na reação com hipoclorito ${ }^{(63)}$ porém, a maioria dos métodos existentes en contraria um interferente nos lons fosfônio existentes na solução, provenientes de irldio (IV). Portanto, antes da aplicação de um dêsses métodos na determinação de rb-. dio, seria necessárío proceder à destruição dos lons fos fônio da solução. A fim de evitar tal incoveniente e considerando a possibilidade de estabelecermos um esque ma de separação, fomos levados a utllizar lons fosfônio para a determinação de $\mathrm{Rh}$ (III) havendo, para isso, necessi- 
dade de se empregar outro intion complexante, como ficou esclarecido no capitulo IV.o azoteto-complexo de Rh(III) precipitado com lons trifenil n-propil.: fosfônio e extra1 do em cloroformio, apresentou espectro de absorção bastante semelhante ao encontrado por MAJUMDAR a MITRA

e composição correspondente ao encontrado por sCHMLDTKB e GARThOFr (65). A extração do azoteto-complexo em ques tão apresentou, como se relatou, margem de êrro pequena.

A separação de Og(IV) de $P d(I I)$ e Pt(IV), se bem que trabalhosa, apresenta bons resultados ainda mais evidenciados pelo fato de haver pouquissimos! mêto dos de separação de Os(IV)em mistura com Pt(IV) e Pd(II) que não utilizam a destilação de $0 \mathrm{SO}_{4}{ }^{*}$ A determinação de Os(IV), ap6s separação, poderia ser efetuada por qual quer um dos métodos já existentes porém, preferimos detemina-10 como o fizemos a fim de tornar mais simples o procedimento. Pelo que ficou exposto na díscussão ido procedimento, todos os dados colhidos indicam a existência de $0 \mathrm{SCl}_{6}{ }^{-}$na solução final, em presença de $\operatorname{SCN}^{-}$e $\mathrm{snCl}_{12}$ havendo provalvelmente, una reducão gradativa/de Os(IV) e Os(III), sendo que medidas precisas de absorbâncila podem ser efetuadas atê cêrca de 50 minutos àpos - inficio da operação de separação. Porém, foi verificado que, se nessa solução final, se adictonar $\mathrm{MnO}_{4}^{-}$laté leve excesso, seguido de adição de solução de acido ascórbico, as gôtas, ate a solução tornar-se limpida e pos teriormente de $\mathrm{HCl}$, ter-se-a uma solução que apresentara absorbâncla constante por algumas horas; a presença de 
Os(IV) em contato com dcido ascorbico foi constatada por MEHROTRA e MUSHRAN (66). Além do acido ascórbico como re dutor de permanganato, pode-se usar tamberm $\mathrm{SnCl}_{2}$, se se usar uma solução de ácido ascbrbico no máximo a 1\%, realmente se obterá constancia nas leituras de absorbância por algumas horas; porên, se se usar solução mais concentrada, há a possibilidade de se ter a solução de os(IV) com valo res de absorbancia crescente no decorrer do tempo. Tal fa to es devido a possibilidade de ácido ascórbico complexar os(IV) (67). quando em solução bastante concentrada (cêrca de 9\%). No nosso, caso, apos descoramento do permanganato, a quantidade de ácido ascórbico que permanece junto a Os(IV) e insignificante e,portanto, não exerce maiores in fluências. Contudo, para uma segurança total, adotamos no nosso procedimento o uso de $S n \mathrm{SI}_{2}$ para reduzir permangana to uma vez que $s n(I I)$ pode permanecer em presença de os(IV) sem que ocorra reduçöes (68).

\section{DETALHES EXPERIMENTAIS}

VIIIa. Reagentes, soluções e apareinagem.

Sais de fosfônio: cloreto de trifenil n-propil fosfonio e cloreto de trifenil i-propil fosfonio foram pre parados por sintese (38). Num frasco de paredes grossas. adicionamse $8,0 \mathrm{~g}$ de trifenil fosfin e $8,0 \mathrm{ml}$ de haleto de alquila (iodeto ou brometo de n-propila ou brometo de i-propila). Apos a vedação total, o frasco e colocado em banho-maria durante cêrca de 12 horas en se tratando da reação com brometo de alquila e por io horás en se tratan 
do da reação com iodeto de alquila. Durante o aquecimen to, o frasco é protegido de Iuminosidade. Após êsse perlodo, deixa-se o frasco resfriar; o mesmo $b$ aberto e adiciona-se éter etilico ao seu interior com o que a mas sa solida agitada a fim de se extrair o excesso de haleto de alquila e de trifenil fosfïnà. Após êsse proce dimento, transfere-se a massa soblida a un erlenmayer de $250 \mathrm{ml}$ e adiciona-se AgCl recém preparado e $150 \mathrm{ml}$ de agua. Coloca-se em banho-maria por 8 horas, agitandorse de tempos em tempos. 0 erlenmayer e recoberto com papel ou pano prêto a fim de se evitar decomposições. Esfria-se, filtra-se e o filtrado é evaporado em banho-maria. A seguir, dissolve-se o mesmo com a minima quantidade de álcool etilico, filtram-se as impurezas e adicio na-se eter etflico o que ocasiona precipitação do cloreto de trifenil alquil fosfônio. Filtra-se em funil de buchner e deixa-se secar. os pontos de fusão dos sais assim obtidos foram:

$\begin{array}{ll}\text { cloreto de trifenil n-propil fosfônio } & 220-224^{\circ} \mathrm{C} \\ \text { cloreto de trifenil i-propil fosfônio } & 251-255^{\circ} \mathrm{C}\end{array}$ As soluções de $\operatorname{Ir}($ IV), $R$ h(III) e Os(IV), foram obtidas pe las dissoluções em $\mathrm{HCl} 0,1 \mathrm{~N}$ dos compostos, respectivamen te, $\left(\mathrm{NH}_{4}\right)_{2} \mathrm{IrCl}_{6},\left(\mathrm{NH}_{4}\right)_{3} \mathrm{RhCl}_{6} \cdot 11 / 2 \mathrm{H}_{2} \mathrm{O}$ e $\left(\mathrm{NH}_{4}\right)_{2} \mathrm{OsCl}_{6}$, de procedência Johnson, Matthey \& Co. Limited. As soluções em questão foram padronizadas: a de Ir(IV)pela redū ção com ácido formico (69); a de Rh(III) pelo método de HAINES e RYAN ${ }^{(70)}$, melhorado por DUVAL ${ }^{(71)}$ e a de os(IV) pelo método de NEEB ${ }^{(32)}$. Cada uma das soluções prepara- 
das apresentou o metal numa concentração da ordem de $1 \mathrm{mg} /$ M1. Preparou-se, por sintese, cloroiridiato de s6́dio ${ }^{(72)}$. cuja solução foi usada em testes qualitativos.

Soluções de lons interferentes: foram preparadas pela dissolução dos sais puros em água (ou ácido quando necessário). Preparo de bromo-complexos de iridio e rodio: à solução de $\mathrm{IrCl}_{6}{ }^{-}$adicionou-se em excesso uma solução de lons brometo (solução de NaBr a 50\%) e aqueceu-se em banho-maria por 20 minutos. A solução final torna-se azul (essa côr começa a se desenvolver a partir de $60^{\circ} \mathrm{C}$ ). As amostras dessa solução, apbs resfriamento, adicionaram-se soluções de cloreto de trifenil n-propil e trifenil i-propil fosfônio. Em cada caso, os precipitados foram estudados em função da extração com os solventes.

A solução de cloro-complexo de $\mathrm{Rh}$ (III) sofreu idêntico procedimento.

Verificação da lei de Beer para cloromcomplexos de Ir(IV): as extrações foram efetuadas num funil de separação de 5 ml de capacidade, a fim de se verificar a lei de Beer. Ao funil adicionou-se $1,0 \mathrm{ml}$ de solução de cloroiridiato,0,15 $\mathrm{ml}$ de HCl 12N, 1,0 ml de solução de trifenil n-propil fosfônio a $2 \%$ e $1,0 \mathrm{ml}$ de clorofórmio. Após agitação, com movimentos circulares aplicados ao funil, conseguiu-se a separação da fase orgânica, a qual foi transferida diretamente a um balão volumétrico de $10 \mathrm{ml}$. A solução do funil, adicionou-se mais três porções de clorofórmio de 1,0 mi de cada, a fim de se lavar a solução. Completou-se o volume do balão com clorofórmio e mediu-se contra um "bran 
con contendo todos os reagentes, a exceção de $\operatorname{Ir}(\mathrm{IV})$. Aparel hagem: nas separações, usou-se funil marcanManostat", de capacidade $20 \mathrm{ml}$, tipo "pêra" com torneira de tefion.

As medidas espectrofotometricas foram efetuadas nos espectrofotômetros Beckman modêlo DU e zeiss modêlo PMQ II. Utilizaram-se cubas de "Corex" de $1,00 \mathrm{~cm}$ de espes sura.

VIIIb. Eliminação de interferentes.

$A u(I I I)$ : a solução inicial contida no funil, adiciona-se $1,0 \mathrm{mi}$ de $\mathrm{HCl} 12 \mathrm{~N}$ e efetua-se a extração do cloro-complexo de $\mathrm{Au}$ (III) com eter etilico, usando-se 3 porções de $2 \mathrm{ml}$ cada. Quando se elimina $\mathrm{Au}$ (III), não há necessidade de se adicionar posteriormente HCl a $s \phi-$ luçầo.

Vanádio: na solução inicial adiciona-se cêrca de $0,3 \mathrm{ml}$ de água oxigenada a $10 \%$, obtendo-se uma forma de vanádio que nho precipita com ions fosfônio e nem extraida em cloroformio. Em seguida. adiciona-se cêrca de $0,3 \mathrm{ml}$ de água de cloro e o procedimento normal é efetuado.

Iodeto: sua eliminação é feita pela adição a solução inicial, no funil, de $0,1 \mathrm{ml}$ de água oxigenada a 10 volumes, $0,05 \mathrm{ml}$ de $\mathrm{HCl}$ 12N e traços de ion molibdá. to (1 gôta de solução a $0,5 \%$ ). o iôdo extraído em 2 inl de benzeno. Agita-se, deixa-se em repouso por al- 
guns minutos $e$, com o auxilio de uma pipeta de extração, retira-se a fase orgânica. A solução remanescente 1 lavada com duas porções de benzeno de $1 \mathrm{ml}$ cada, apbs o que o procedimento normal $e$ aplicado.

Brometo: a solução inicial contendo fons brometo, adiciona-se $0,5 \mathrm{ml}$ de sgua de cloro (saturada)0,05 $\mathrm{ml}$ de $\mathrm{HCl} 12 \mathrm{~N}$ e $1 \mathrm{ml}$ de cloroformio. Agita-se e elimina se o bromo. Lava-se a solução com mais duas porções de $1 \mathrm{ml}$ cada de cloroformio e segue-se o procedimento nor mal.

Iodeto-brometo: nêsse caso, prefere-se eliminar o iôdo por meio de clorofórmio utilizando-se água oxigenada e traços de molibdato:. (descrito acima)sendo necessárias 3 porções de $1 \mathrm{ml}$ cada de clorofórmio, após - que aplica-se o processo de eliminação de brometo descrito acima.

Tiocianato: à solução de partida contendo lons tiocianato, adiciona-se $0,05 \mathrm{ml}$ de $\mathrm{HCl} 12 \mathrm{~N}$ e a seguir cuidadosamente, às gôtas, adiciona-se uma solução de per manganato $0,5 \mathrm{~N}$ até leve excesso. A seguir, adiciona-se, às gôtas, solução de ácido ascórbico $0,5 \%$ até completa redução do excesso de permanganato e, em seguida, o precedimento é aplicado.

vIIIc. Isolamento e análise dos compostos.

Iridio: a uma solução de $\operatorname{IrCl}_{6}^{--}(\mathrm{em}$ HC1 $0,1 \mathrm{~N})$, 
adicionou-se excesso de lons trifenil n-propil fosfônio e aqueceu-se a $50^{\circ} \mathrm{C}$ durante uma hora. Filtrou-se, lavou se o precipitado e o mesmo foi secado sob baixa pressão.

$$
\left[\phi_{3}{ }^{P-C} 3_{7 n}^{H}\right]_{2}\left[\mathrm{IrCl}_{6}\right]
$$

Calculado: Ir-18,91\%; P-6,10\%

Obtido: Ir-18,72\%: P-5,85\%

0 composto en questão possui côx castanho-aver mel hada e P.F. $246-247^{\circ} \mathrm{C}$.

o iridio foi analisado pela redução com ácido formico (69), sendo a filtração do iridio efetuada em pôlpa de papel ao inves de plaquinha de sllica. Quanto ao fósforo, após destruição do composto, dețerminou-se o fosfato resultante como pirifosfato de magnésio.

R6dio: a una solução de $\mathrm{RhCl}_{6}{ }^{--}$(em HCl $0,1 \mathrm{~N}$ ), adicionou-se excesso de lons azoteto e aqueceu-se a cêrca de $60^{\circ} \mathrm{C}$ durante uma hora. Ap8s resfriamento, adicionou-ge excesso de lons trifenil n-propil fosfônio, deixou-se decantar e filtrou-se; apbs lavagem do precipitado, o mesmo foi secado sob baixa pressão.

$$
\left[\phi_{3} \mathrm{P}-\mathrm{C}_{3} \mathrm{H}_{7 \mathrm{n}}\right]_{3}\left[\mathrm{Rh}\left(\mathrm{N}_{3}\right)_{6}\right]
$$

$$
\begin{array}{r}
\text { Calculado: } \mathrm{Rh}-8,10 \% ; \mathrm{P}-7,32 \% ; \mathrm{N}-19,84 \% \\
\text { Obtido: } \mathrm{Rh}-7,82 \% ; \mathrm{P}-7,08 \%: \mathrm{N}-19,72 \%
\end{array}
$$

o composto possui côr vermelha e P.F.133-134 ${ }^{\circ} \mathrm{C}$. 
o rodio, apos destruição do composto, foi ana 1isado pelo método de HAINES e RYAN $(70)$ melhorado por DUVAl (71). Quanto ao fosforo, sua análise foi idêntica a efetuada para o composto de iridio. Com relação a análise de azoteto, utilizou-se o metodo de SOMMER. e PINCAS $(73,74)$, pelo emprêgo de Ce(IV) em excesso, seguido da adição de iodeto e a titulação com tiossulfato. 
SUMARIO

A extratibilidade de sais de fosfônio foi apro veitada para elaborar método de separação Ir-Rh, mediante a extração do sal de trifenil n-propil fosfônio do cloro-complexo de Ir(IV) em cloroformio. o coeficiente de extração de $99,2 \%$, permite retirar o iridio do meio aquoso com grande eficiência. o. iridio assim separado $\varepsilon$ determinado diretamente, por via espectrofotometrica, em $494 \mathrm{m \mu}$. em faixa de concentração de 5,0 a 50,0 $\mathrm{\mu g} / \mathrm{ml}$. Pd(II), Pt(IV) e Os(IV) interferem e são eliminados prèviamente, assim como $\mathrm{Au}$ (III). Os ânions interferentes, $\mathrm{I}^{-}, \mathrm{Br}^{-}$e $\mathrm{SCN}^{-}$são também eliminados prèviamente. Muitos lons podem estar presentes, tais como Co(II), Cu(II), $\mathrm{Mn}(\mathrm{II}), \mathrm{Fe}(\mathrm{III}), \mathrm{Ni}(\mathrm{II}), \mathrm{As}(\mathrm{V}), \mathrm{Sb}(\mathrm{V}), \mathrm{NO}_{3}^{-}, \mathrm{ClO}_{4}^{-} \mathrm{e}$ $\mathrm{SO}_{4}^{--}$.

Apbs a separação do $\operatorname{Ir}($ IV), O $R h$ (III) que permanece, na solução é complexado com lons azoteto e extra1 do em clorof6rmio depois de precipitado com lons trifenil n-propil fosfônio, sendo o coeficiente de extração de 98,3\%. A determinação é também feita no próprio solvente, mediante medida espectrofotométrica em 404-408 $m \mu$, para um intervalo de concentração de 10,0 a 70,0 $\mu \mathrm{g} / \mathrm{ml}$.

Uma separação envolvendo Os(IV), Pd(II)e Pt(IV) 
foi elaborada, eliminando-se Pd(II) e Pt(IV) por extracão de ambos em metil n-butil cetona a partir de uma solução contendo $\operatorname{scN}^{-}$. 0 Os(IV) é determinado na solução aquosa na forma de $\mathrm{OsCl}_{6}{ }^{--}$por medida espectrofotométri ca em $370 \mathrm{~m}_{\mu}$, vallida para a faixa de concentração de 2,0 a $20,0 \mu \mathrm{g} / \mathrm{ml}$. 


\section{BIBLIOGRAFIA}

1. F.E.BEAMISH, "The Analytical Chemistry of the Noble Metals". Pergamon Press, Oxford,1966 p. 56

2. W. GIBBS, Chem. News, I, 61, 73, 97 (1863);F.E.BEAMISH, idem, p. 57 .

3. N.K.PSHENITZYN, I.A.FEDEROV E P.V.SIMANOVISKII, Obshchei i Nerrg. Khim. Akad. Nauk SSSR, 22, 22 (1948); C.A. 44, 10583 (1950).

4. R.GILCHRIST, Bur. Sts. J. Research, 9, 547 (1932); C.A. 27, 2650 (1932).

5. V.M.MUKHACHEV, Zavodskaya Lab., 12, 927 (1946); C.A. 41, 4736 (1947).

6. S.AOYAMA e K.WATANABE, J. Chem. Sec. Japan, 75, 20 (1954) e 76, 597, (1955); C.A. 48, 8118 (1954) e $50,136 \overline{59}$ (1956).

7. G.G.TERTIPIS e F.E.BEAMISH, Anal. Chem., 32, 486 (1960).

8. A.D.WESTLAND e F.E.BEAMISH, Mikrochim. Acta, 10, 1474 (1956).

9. A.D.WESTLAND e F.E.BEAMISH, Mikrochim Acta, 5, 625 (1957)

10. W.B.POLLARD, Bull. Inst. Mining. Met., 497, 9 (1948): C.A. 42, 4489, (1948).

11. N.K.PSHENITSYN, Inst. Obs. Neorg. Khim. Akad. Nauk SSSR, 22, 7 (1948); C.A. 44, 10585 (1950).

12. M.L.CLUETT, S.S.BERMAN E.W.A.E.MC BRYDE, Analyst, 80, 204. (1955). 
13. W.M.MC NEVIN E E.S.Mv KAY, Anal. Chem., 29, 1220 (1957).

14. S.S.BERMAN E W.A.E.MC BRYDE, Can. J. Chem., 36 835 (1958).

15. E.W.BERG E W.L.SENN JR., Anal. Chem., 27, 1255 (1955).

16. G.G.TERTIPIS e F.E.BEAMISH, Anal, Chem., 34, 623 (1962).

17. E.W.BERG e W.L.SENN, Anal. Chim. Acta, 19, 109 (1958).

18. R.B.WILSON e W.D.JACOBS, Anal. Chem., 33, 1650 (1961).

19. G.H.FAYE E W.R. INMAM, Anal. Chem. 35, 985 (1963).

20. S.E.KASHLINSKAYA, I.I.LITVINSKAYA E N.P.STELNIKOVA, Zaved Lab.. 33, 925 (1967); C.A. 67, 11500 (1967).

21. N.V.FEDORENKO e T.I.IVANOVA, Ah. Neorg. Khim., 10, 721 (1965); Anal. Abst., 13, 2977 (1966).

22. V.F.BORBAT, P.I.BOBIKOV e E.F.KOUBA, Zh. Anal. Khim. 20, 192 (1965); Anal. Abstr., 13, 4870 (1966).

23. M.Y.MIRZA, M.E.JAZ, A.R.SANI, S.ULLAH, M.RASHID E G.SANDANI, Anal. Chim. Acta, 37, 402 (1967).

24. A.A.VASILEVA, L.M.GUINDIN, S.M.IVANOVA, L.Y.MIRANOVA e G.I.SMIRNOVA, Izv. Sib. Otd. Akad. Nauk. SSSR, 174 (1967); C.A. 67, 11495 (1967).

25. W.F.BORBAT e O.B.TIKHOMIROV, Tsvet. Metal. 40, 30 (1967); C.A. 67, 6296 (1967).

26. L.M.GUINDIN, S.N.IVANOVA, A.A.MAZUROVA, A.A.VASILEVA, L.MIRONOVA, A.P. SOROLOV E P.P.SMIRNOV, IzV. Sib. Otd. Akad. Nauk. SSSR, Sr. Khim. Nauk., 1. 89 (1967); C.A. 67, 68138, (1967). 
27. L.M.GUINDIN, S.N.IVANOVA E I.MIRONOVA, IzV. Sib. Otd. Akad. Nauk. SSSR 11. (1964) e Ser. Kim. Nauk. SSSR 11. (1964) e Ser. Khim. Nauk., 3, 157: Anal. Abstr.. 2979 (1966).

28. J.W.MURPHY E H.E.AFPSPRUNG, Anal. Chem., 33. 1658 (1961).

29. R.NEEB, Z. Anal. Chem., 152, 159 (1956).

30. R.NEEB, Z. Anal, Chem., 159, 401 (1958).

31. R.NEEB, Z. Anal . Chem., 154, 24 (1957).

32. R.NEEB, Z. Anal. Chem., 177, 20 (1960).

33. R.NEEB, Z. Anal. Chem., 177, 420 (1960).

34. H.BODE, Z. Anal, Chem., 133. 95 (1951).

35. R.J.MAGEE e M.A.KHATtAK, Z. Anal. Chem., 8. 285 (1964).

36. R.NEEB, Z. Anal. Chem., 154, 17 (1957).

37. R.NEEB e K.KHAN-BOLUKI, Z. Anal, Chem., 215, 392 (1966).

38. P.SENISE e L.R.M.PITOMBO, Anais AssOC. Bras. Química, 20. 93 (1961).

39. P.SENISE e I.R.M.PITOMBO, Anal. Chim. Acta, 26, 85 (1962).

40. P.SENISE e L.R.M.PITOMBO, Anal. Chim. Acta, 26, 89 (1962).

41. P.SENISE e I.R.M.PITOMBO, Talanta, 11, 1185 (1964).

42. GMELINS Handbuch der Anorganischen Chemie, system Nummer 67. 1939, p. 72.

43. GMELINS Handbuch der Anorganischen Chemie, System Nummer 69. 1939, p. 96. 
44. J.MEYBR E K.HOEHNE, 2. Anorg. Allgem, Chem., 231. 372 (1937).

45. J.MEYER, M.KAWCZYK E K.HOEHNE, Z. AnOTg. All gem. Chem.. 232, 410 (1937).

46. A.RINGBOM, Z. Anal. Chem., 115, 585 (1939).

47. F.MYLIUS A C.hUTTHER, Ber.. 44, 1315 (1911).

48. J.K.CARLTON, Anal, Chem., 22, 1072 (1950).

49. J.H.WIERSMA e P.F.LOTT, Anal, Chem., 39, 674 (1967).

50. R.G.CLEM e E.H.HUFFMAN, Anal. Chem., 37, 86 (1965).

51. R.L.RICH e H.TAUBE, J.Am, Chem, SOC., 76, 2608 (1954).

52. J.S.LITTLER, J. Chem. SOc., 832 (1962).

53. W.A.WATERS, Mechanisms of Oxidation of Oxganis Compounds" John Wiley \& Sons Inc., 1964, p. 99.

54. G.H.AYRES e W.T.BOLLETER, Anal. Chem., 29, 72 (1957).

55. S.S.BERMAN E W.A.E.MC BRYDE, Analyst, 81, 566 (1956).

56. F.E.BEAMISH, "The Analytical Chemistry of the Noble Metal s". Pergamon Press, Oxford, 1966, p."422.

57. G.H.AYRES e Q.QUICK, Anal. Chem., 22, 1403 (1950).

58. N.K.PSHENITSYN, S.I.GINZBURG E L.G.SALSKAYA, Zhur. Neorg. Khim., 4, 301, (1959): C.A. 53, 12913 (1959).

59. A.D.MAYNES E W.A.E.MC BRYDE, Analyst, 79, 230 (1.954).

60. A.D.WESTLAND E F.E.BEAMI SH, Anal, Chem., 27, 1776 (1955).

61. S.S.BERMAN, F.E.BEAMISH E W.A.E.MC BRYDE, Anal. Chim. Acta, 15, 363 (1956). 
62. R.B.WILSON E W.D.JACOBS, Anal. Chem., 33, 1650 (1961).

63. G.H.AYRES E F.YOUNG, Anal. Chem., 24, 165 (1952).

64. A.K.MAJUMDAR E B.X.MITRA, Anal. Chim. Acta, 33, 670 (1965).

65. H.H.SCHMIDTKE C D.GARTHOFF, J.Am. Chem, SOC., 89, 1317. (1967).

66. U.S.MERROTRA E S.D.MUSHRAN, Can. J. ChEm., 48, 1148, (1970).

67. K.P.STOLYAROV E I.A.AMANTOVA, Talanta, 14. 1237 (1967).

68. R.NEEB, Z. Anal, Chem., 215, 392 (1966).

69. C.DUVAL, P.CHAMP e P.FAuCONNIER, Anal. Chim. Acta, 20, 152 (1959).

70. R.L.HAINES E D.E.RYAN, Can. J. Res.. 27B, 72 (1949): F.E.BEAMISH, "The Analytical Chemistry of the Noble Metals". Pergamon Press, Oxford, 1966. P. 267.

71. C.DUVAL, P.ChaMp e P.FAUCONNIBR, Anal., Chim. Acta, 12. 138 (1955).

72. R.R.BAREFOOT, W.J.MC DONNEL E F.E.BEAMISH, Anal Chem. 25. 514 (1951).

73. F.SOMIER E H.PINCAS, Ber. 48, 1963 (1915).

74. P.J.DURRANT e B.DURRANT. "Introduction Advanced Inorganic Chemistry" Longmans, 1962, P. 685. 